\title{
Invasive non-typhoidal Salmonella infections in sub-Saharan Africa: a systematic review on antimicrobial resistance and treatment
}

\author{
Bieke $\operatorname{Tack}^{1,2^{*}}$ (D) Jolien Vanaenrode ${ }^{3}$, Jan Y. Verbakel ${ }^{4}$, Jaan Toelen ${ }^{5,6}$ and Jan Jacobs ${ }^{1,2}$
}

\begin{abstract}
Background: Non-typhoidal Salmonella (NTS) are a frequent cause of invasive infections in sub-Saharan Africa. They are frequently multidrug resistant (co-resistant to ampicillin, trimethoprim-sulfamethoxazole, and chloramphenicol), and resistance to third-generation cephalosporin and fluoroquinolone non-susceptibility have been reported. Thirdgeneration cephalosporins and fluoroquinolones are often used to treat invasive NTS infections, but azithromycin might be an alternative. However, data on antibiotic treatment efficacy in invasive NTS infections are lacking. In this study, we aimed to assess the spatiotemporal distribution of antimicrobial resistance in invasive NTS infections in sub-Saharan Africa and to describe the available evidence and recommendations on antimicrobial treatment.
\end{abstract}

Methods: We conducted a systematic review of all available literature on antimicrobial resistance and treatment in invasive NTS infections. We performed a random effects meta-analysis to assess the temporal distribution of multidrug resistance, third-generation cephalosporin resistance, and fluoroquinolone non-susceptibility. We mapped these data to assess the spatial distribution. We provided a narrative synthesis of the available evidence and recommendations on antimicrobial treatment.

Results: Since 2001, multidrug resistance was observed in 75\% of NTS isolates from all sub-Saharan African regions (95\% confidence interval, $70-80 \%$ and 65-84\%). Third-generation cephalosporin resistance emerged in all subSaharan African regions and was present in 5\% (95\% confidence interval, 1-10\%) after 2010. Fluoroquinolone nonsusceptibility emerged in all sub-Saharan African regions but did not increase over time. Azithromycin resistance was reported in DR Congo. There were no reports on carbapenem resistance. We did not find high-quality evidence on the efficacy of antimicrobial treatment. There were no supranational guidelines. The "Access group" antibiotics ampicillin, trimethoprim-sulfamethoxazole, and chloramphenicol and "Watch group" antibiotics ceftriaxone, cefotaxime, and ciprofloxacin were recommended as the first-choice antibiotics in national guidelines or reviews. These also recommended (a switch to) oral fluoroquinolones or azithromycin.

(Continued on next page)

\footnotetext{
* Correspondence: btack@itg.be

'Department of Clinical Sciences, Institute of Tropical Medicine, Antwerp, Belgium

2Department of Microbiology, Immunology and Transplantation, KU Leuven, Leuven, Belgium

Full list of author information is available at the end of the article
}

C The Author(s). 2020 Open Access This article is licensed under a Creative Commons Attribution 4.0 International License, which permits use, sharing, adaptation, distribution and reproduction in any medium or format, as long as you give appropriate credit to the original author(s) and the source, provide a link to the Creative Commons licence, and indicate if changes were made. The images or other third party material in this article are included in the article's Creative Commons licence, unless indicated otherwise in a credit line to the material. If material is not included in the article's Creative Commons licence and your intended use is not permitted by statutory regulation or exceeds the permitted use, you will need to obtain permission directly from the copyright holder. To view a copy of this licence, visit http://creativecommons.org/licenses/by/4.0/ The Creative Commons Public Domain Dedication waiver (http://creativecommons.org/publicdomain/zero/1.0/) applies to the data made available in this article, unless otherwise stated in a credit line to the data. 
(Continued from previous page)

Conclusions: In addition to the widespread multidrug resistance in invasive NTS infections in sub-Saharan Africa, resistance to third-generation cephalosporins and fluoroquinolone non-susceptibility was present in all regions. There was a lack of data on the efficacy of antimicrobial treatment in these infections, and supranational evidencebased guidelines were absent.

Keywords: Non-typhoidal Salmonella, Invasive infections, Sub-Saharan Africa, Antimicrobial resistance, Antimicrobial treatment

\section{Background}

Globally, non-typhoidal Salmonella (NTS) are an important cause of foodborne and self-limiting enteritis [1]. In sub-Saharan Africa, however, NTS frequently invade normally sterile sites and cause invasive infections [2]. Most of these invasive NTS infections are bloodstream infections, but also meningitis and other focal infections occur [3]. In bloodstream infections, NTS is one of the three most isolated pathogens in sub-Saharan Africa [4]. In addition, in 2017, it was estimated that $79 \%$ of the 535,000 global cases of invasive NTS infection occurred in this region. Moreover, $85 \%$ of the estimated 77,500 deaths worldwide occurred in sub-Saharan Africa, corresponding to a high case fatality ratio of $15.8 \%$ [1]. Most invasive NTS infections occur in susceptible hosts, i.e., HIV-infected individuals or young children with comorbidities like Plasmodium falciparum malaria infection, anemia, or malnutrition [5]. Most infections are caused by Salmonella enterica subspecies enterica (hereafter Salmonella) serovars Typhimurium and Enteritidis [4]. For both serovars, the strains circulating in sub-Saharan Africa have different genotypes than the ones circulating in high-income countries. The sub-Saharan African strains have a more human-adapted and more virulent genotype and phenotype. In addition, they frequently carry antimicrobial resistance (AMR) genes $[3,6]$.

Multidrug resistance (MDR), i.e., co-existing resistance to ampicillin, trimethoprim-sulfamethoxazole, and chloramphenicol, is currently widespread among NTS in sub-Saharan Africa [3]. All three antibiotics are categorized by the World Health Organization (WHO) model list of essential medicines as "Access" antibiotics and thus recommended as an empiric first-choice treatment for many infectious syndromes, including invasive infections [7, 8]. Alarmingly, third-generation cephalosporin (C3G) resistance and fluoroquinolone non-susceptibility (FQNS) have now been reported in various countries in sub-Saharan Africa [3]. Both antibiotic classes are listed as "Watch" antibiotics, because they are considered as critically important antibiotics for human medicine [9] and they are at high risk of selecting bacterial resistance. As such, they are prioritized as key targets of stewardship programs and monitoring $[7,8]$.
The WHO Global Action Plan against Antimicrobial Resistance highlights both the importance of strengthening the current knowledge through surveillance and optimizing the use of antibiotics [10]. Firstly, although many studies report surveillance data on the presence of MDR, C3G resistance, and FQNS, these data have never been clustered to assess their temporal evolution and spatial distribution in sub-Saharan Africa. Secondly, the optimal use of antibiotics to treat invasive NTS infections is unknown. To the best of our knowledge, no supranational guidelines on the antimicrobial treatment of invasive NTS infections exist, and no data on the efficacy of antimicrobial therapy in invasive NTS infections are available from interventional or high-quality observational studies. As a consequence, clinicians currently use antimicrobial regimens that are mimicked from antimicrobial regimens for typhoid fever [5].

In this systematic review, we aim to assess the temporal and spatial distribution of AMR in invasive NTS infections in sub-Saharan Africa. We focus on MDR, C3G resistance, and FQNS, as these cover the main antibiotics used to treat invasive NTS infections. Secondly, we collect and describe all available evidence on antimicrobial treatment efficacy and safety in invasive NTS infections. Finally, we collect and summarize the recommendations regarding the antimicrobial treatment of invasive NTS infections published in research or review articles and supranational or national guidelines.

\section{Methods}

\section{Search strategy and study selection}

We conducted a systematic review of the literature according to the PRISMA guidelines (Additional File 1: Table S1). The study protocol has been publicly registered at study initiation (PROSPERO, CRD42019137673). We searched for all studies published from inception until 29 January 2020 on four databases: MEDLINE, Ovid Embase, African Journals Online, and African Index Medicus. The search strategy was developed together with a biomedical librarian (MJ).

For the first research question on the temporal and spatial distribution of AMR in invasive NTS infections in sub-Saharan Africa, we used the following search 
concepts: "antimicrobial resistance" and "non-typhoidal Salmonella" and "invasive infection" and "sub-Saharan Africa". For the second research question on the available recommendations and therapeutic efficacy data, the search concepts were as follows: "antimicrobial treatment" and "non-typhoidal Salmonella" and "invasive infection". The full search strategies for both review questions in MEDLINE and Ovid Embase are provided in Additional File 1: List S2. We used adapted versions of these strategies in the two African databases. We completed our search by scanning the reference lists of review articles encountered during the search.

Only full-text articles or guidelines were considered as eligible, i.e., non-full text conference proceedings or book chapters were excluded. Only studies published in English, French, Spanish, Portuguese, and Dutch were eligible for inclusion. Two independent reviewers (BT, JVA) screened the articles for eligibility according to the in- and exclusion criteria mentioned in Additional File 1: Table S3. The screening was performed in Qatar Computing Research Institute (QCRI, Doha, Qatar). Any conflict was resolved by a discussion.

\section{Data extraction}

For review question 1, we extracted the study metadata, methods, and results from antibiotic susceptibility testing (number of tested NTS and number of resistant NTS or proportion of resistant NTS). For review question 2, we extracted clinical outcomes and adverse event data from interventional and observational studies and documented the antimicrobial treatment recommendations from guidelines and reviews. The data were extracted by one reviewer (JVA) and checked by a second reviewer (BT). All extracted data were compiled in an Excel database (Microsoft, Redmond, WA, USA) (Additional File 2).

\section{Risk of bias assessment}

The risk of bias was assessed by one reviewer (JVA) and checked by a second reviewer (BT) (Additional File 3). For research question 1, the MICRO checklist [11] and the Joanna Briggs Institute Critical Appraisal Checklist for Studies Reporting Prevalence Data [12] were used. Based on the grading system described in the MICRO checklist, the quality of each study was graded with "A" being the highest quality and " $E$ " being the lowest quality grade.

For research question 2, we used the Joanna Briggs Institute Critical Appraisal Checklist for Quasi-Experimental Studies (non-randomized experimental studies) [13] for studies reporting therapeutic efficacy. For guidelines, we used the AGREE II checklist [14], and for recommendations in expert opinion papers or reviews, the Joanna Briggs Institute Critical Appraisal Checklist for Text and Opinion Papers [15].

\section{Definitions}

Countries were assigned to the geographic regions identified by the United Nations [16]. We considered isolates as resistant when they were reported as resistant or "intermediately resistant" or "intermediately susceptible" or "non-susceptible" [17]. Results for ampicillin and amoxicillin were aggregated. Figure 1 gives an overview of the definitions of MDR [5, 23, 24], C3G resistance, and FQNS $[18,22,24,25]$ used in this review.

For C3G resistance and FQNS, we pooled the data as such that the maximal number of resistant NTS was obtained. Over time, the guidelines for fluoroquinolone susceptibility testing have changed (Fig. 1). These revisions were driven by reports about treatment failure in patients with invasive Salmonella infections. Salmonella, mainly Typhi, isolated from these infections with clinical failure of ciprofloxacin were reported as ciprofloxacin susceptible but demonstrated resistance to nalidixic acid or a moderately increased ciprofloxacin minimum inhibitory concentration (MIC) value $[26,27]$. Ever since, it is discouraged to use fluoroquinolones to treat Salmonella with decreased ciprofloxacin susceptibility (DCS; Fig. 1) [18, 19]. In addition, the use of nalidixic acid as surrogate disk testing is no longer recommended since 2017 due to failure of detection of $\operatorname{gyr} B$ and plasmid-mediated fluoroquinolone non-susceptibility $[18,20,21,25]$.

\section{Data analysis}

For research question 1, we performed a meta-analysis to assess the temporal evolution of MDR, C3G resistance, or FQNS and created a simplified map to assess their spatial distribution in sub-Saharan Africa.

For the meta-analysis about AMR, studies reporting antibiotic susceptibility testing from $<50$ NTS isolates and studies that reported only on resistant isolates were excluded. In addition, we excluded studies with grade $\mathrm{E}$ quality according to the MICRO checklist [11], due to uncertainty or inconsistency in their reported data. To calculate the pooled proportions of MDR, C3G resistance, and FQNS in invasive NTS isolates, we used a random effects restricted likelihood model after double arcsine transformation. Heterogeneity was assessed based on the parameters $I^{2}, \tau^{2}$, and $Q$. We conducted a sensitivity analysis to assess the effect of the exclusion of studies reporting antibiotic susceptibilities of <50 NTS isolates and the inclusion of studies with grade D quality.

To assess the temporal evolution, the meta-analysis was repeated per time period. Based on their midyear, which was rounded to the most recent year, all studies were classified into four time periods: until 1990, 19902000, 2001-2010, and after 2010. Data were disaggregated per period wherever possible. In addition, we performed a subgroup analysis for Salmonella Typhimurium and Salmonella Enteritidis with data from studies that reported $\geq$ 


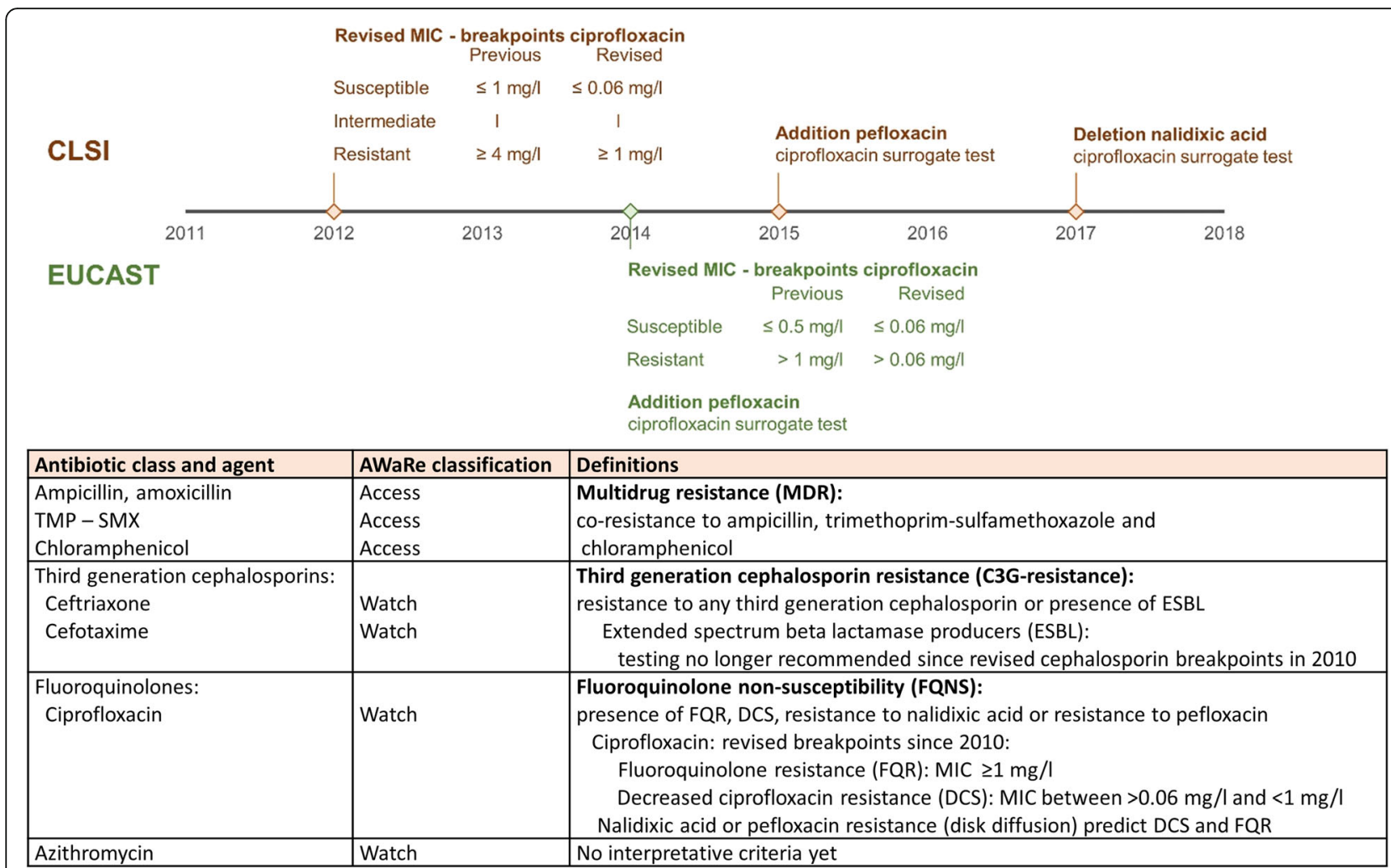

Fig. 1 Overview of the definitions used in this review and of the changes in recommendations for fluoroquinolone susceptibility testing over time. A thin line represents the MIC — range of the intermediate susceptibility category according to CLSI (brown) [18, 19]. There is no intermediate ciprofloxacin susceptibility category defined by EUCAST (green) [22]. The antibiotic agents are classified according to antibiotic class and the AWaRe classification. The latter is defined in the WHO Essential Medicines List and categorizes antibiotics into Access, Watch, or Reserve group antibiotics [7, 8]. TMP-SMX, trimethoprim-sulfamethoxazole; MIC, minimum inhibitory concentration; CLSI, Clinical and Laboratory Standards Institute; EUCAST, European Committee on Antimicrobial Susceptibility Testing

10 isolates per serotype. Finally, we performed a metaregression analysis using a mixed-effect model to assess if part of the residual heterogeneity could be explained by differences in study characteristics. The meta-analysis was done in $\mathrm{R}$ version 3.6 in the "metafor" package (functions escalc(), $r m a()$, predict(), print(), forest()).

Secondly, to assess the spatial distribution of MDR, C3G resistance, and FQNS, we generated a map in PowerPoint Office 16 (Microsoft). For countries without exact data on MDR, we plotted the highest possible proportion of MDR, which was based on the antibiotic (ampicillin, trimethoprim-sulfamethoxazole, or chloramphenicol) with the lowest proportion of resistance.

\section{Results}

Antimicrobial resistance in invasive NTS infections in subSaharan Africa

\section{Study inclusion and characteristics}

We included 53 studies that reported AMR in invasive NTS infections in sub-Saharan Africa (Fig. 2). The studies for which no full text could be retrieved are listed in Additional File 1: List S4. Most studies reported NTS obtained from 2000 onwards, and all four regions of sub-Saharan Africa were represented (Fig. 2). Most studies were hospital-based (40/48) and reported data from blood culture isolates only (43/53; Table 1$)$. The interpretative criteria for the antibiotic susceptibility tests were reported in $74 \%(39 / 53)$, and the version of these criteria was specified in 36 studies. From the 38 studies that reported data on FQNS, only $21 \%$ described DCS and FQR separately. More than half of the studies were considered as grade D quality (31/53). We considered four studies as grade $\mathrm{E}$ quality due to uncertainty or inconsistencies in the data reported [28-31].

\section{Multidrug resistance}

The first report of MDR NTS, published in 1990, described 246 MDR NTS obtained from hospital admitted children in Rwanda between 1982 and 1987. These 246 MDR NTS were also resistant to nalidixic acid, but still susceptible to C3G [32]. The first study that reported the proportion of MDR according to the current definition of MDR for NTS [5, 23] was published in 2012 [33]. Ever since, ten other studies reported the proportion of MDR 


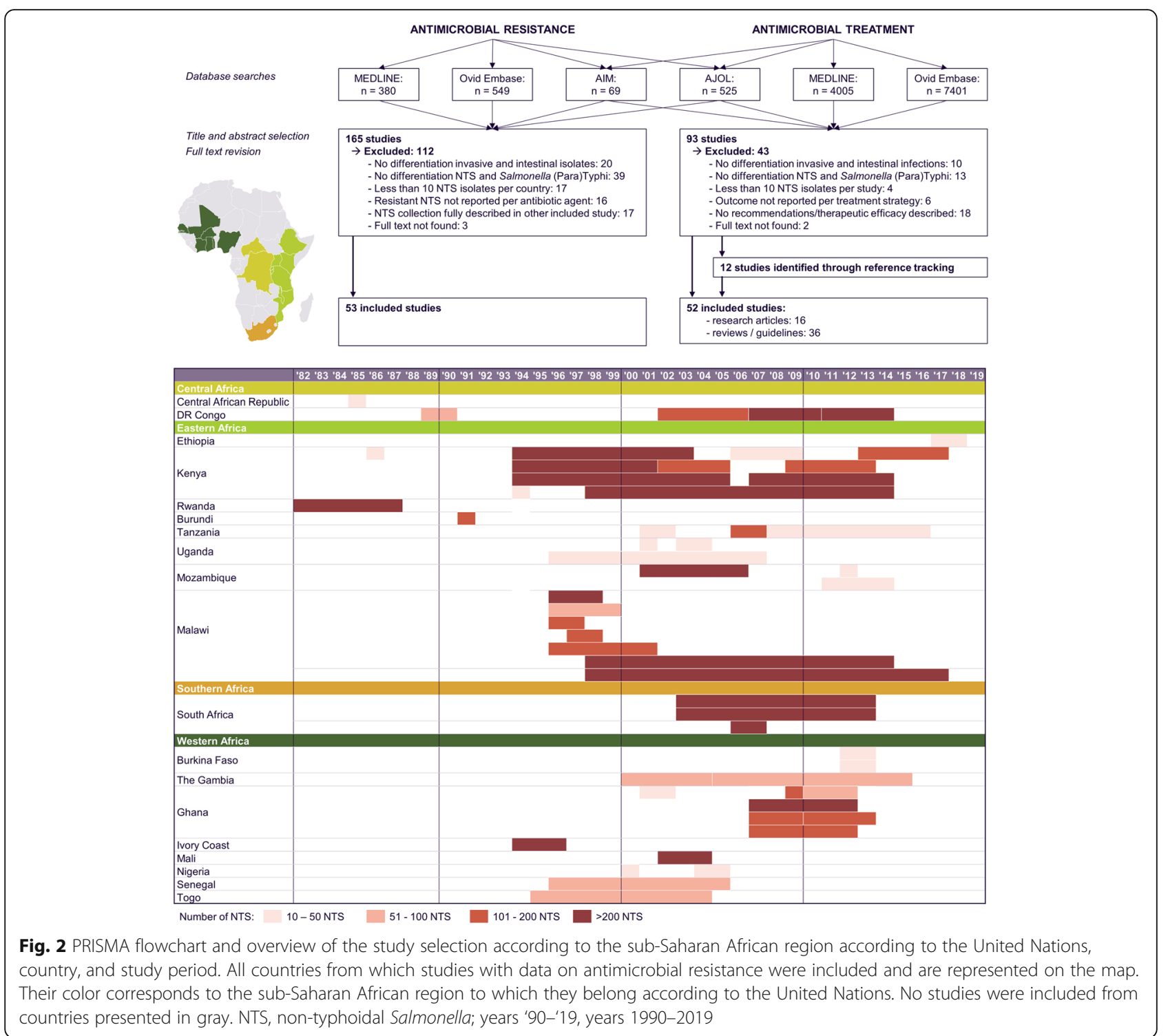

NTS isolates (Figs. 3 and 4) [34-42]. In addition, the absence of chloramphenicol resistance allowed to deduct the absence of MDR in two studies published in 2000-2001 [43, 44].

A meta-analysis revealed an increase in MDR after 2000 , with a pooled MDR proportion of $3 \%$ in the 1990 s versus $75 \%$ afterwards (Fig. 3). These estimates were not impacted by the inclusion of grade D quality studies (Additional File 1: Figure S5). The emergence of MDR after 2000 was observed both in Salmonella Typhimurium and in Salmonella Enteritidis. Although data were scarce, MDR proportions in Salmonella Typhimurium were higher than in Salmonella Enteritidis after 2000. (Additional File 1: Figure S6A). Meta-regression only identified the study period as a significant moderator (Additional File 1: Table S7). Although no data from Southern Africa were included in the meta-analysis, the maximum MDR proportions, plotted in Fig. 4, suggested the emergence of MDR in all four regions of subSaharan Africa.

\section{Third-generation cephalosporin resistance}

The first three NTS strains with C3G resistance were isolated in 1994 in Kenya and were resistant to ceftazidime [45]. Until 2000, C3G resistance was absent in all nine other studies that reported results from C3G testing [30, 46-54]. Since 2001, C3G resistance was reported in 17 [28, 29, 34, 35, 40,42, 49, 50, 54-62] of the 33 studies that reported results from C3G testing $[28,29,33-35,37-40,42,48-69]$. Most $(n=24)$ studies reported data on ceftriaxone susceptibility, whereas cefotaxime susceptibility was reported in ten studies, ceftazidime susceptibility in six studies, and ESBL NTS in 10 studies (Dataset S3). 
Table 1 Study characteristics of the included studies reporting antimicrobial resistance in invasive NTS infections in sub-Saharan Africa

\begin{tabular}{|c|c|c|c|}
\hline Study characteristics - population & n (\%) & Study characteristics - microbiology & n (\%) \\
\hline Region sub-Saharan Africa & $n=53$ & Number of NTS isolates & 53 \\
\hline Central Africa & $5(9)$ & $10-49$ & $15(28)$ \\
\hline Eastern Africa & $31(58)$ & $50-99$ & $8(15)$ \\
\hline Southern Africa & $3(6)$ & $100-199$ & $12(23)$ \\
\hline \multirow[t]{2}{*}{ Western Africa } & $16(30)$ & $200-499$ & $12(23)$ \\
\hline & & $>500$ & $6(11)$ \\
\hline Study design & $n=53$ & & \\
\hline Retrospective & $21(40)$ & Clinical specimen & 53 \\
\hline \multirow[t]{2}{*}{ Prospective } & $32(60)$ & Blood & $43(81)$ \\
\hline & & CSF & $2(4)$ \\
\hline Duration study period & $n=53$ & Blood + CSF & $4(8)$ \\
\hline$<1$ year & $8(15)$ & Blood + CSF + other normally sterile body sites & $4(8)$ \\
\hline $1-2$ years & $11(21)$ & & \\
\hline $2-5$ years & $14(26)$ & Method antibiotic susceptibility testing & 52 \\
\hline $5-10$ years & $8(15)$ & Disk diffusion & $28(54)$ \\
\hline \multirow[t]{2}{*}{$>10$ years } & $12(23)$ & E-test & $1(2)$ \\
\hline & & Automated methods & $2(4)$ \\
\hline Study setting & $n=48$ & Disk diffusion + E-test & $17(33)$ \\
\hline Population based & $3(6)$ & Automated methods + disk diffusion / E-test & $4(8)$ \\
\hline District hospital & $19(40)$ & & \\
\hline University / tertiary care hospital & $12(25)$ & International guidelines for interpretation AST & 39 \\
\hline \multirow[t]{2}{*}{ Multicenter } & $14(29)$ & CLSI / NCCLS & $32(82)$ \\
\hline & & EUCAST & $2(5)$ \\
\hline Study population & $n=50$ & National guidelines (French microbiological society or BSAC) & $5(13)$ \\
\hline Children & $28(56)$ & & \\
\hline Adults & $8(16)$ & Version of guidelines specified & $36(92)$ \\
\hline \multirow[t]{2}{*}{ Children and adults } & $14(28)$ & & \\
\hline & & Definitions of fluoroquinolone non-susceptibility & 38 \\
\hline HIV prevalence & $n=26$ & Mixed reporting of resistance $\&$ decreased susceptibility & $10(26)$ \\
\hline$\leq 20 \%$ in enrolled patients / patients with invasive NTS infection & $9(35)$ & Resistance \& decreased susceptibility separately reported & $8(21)$ \\
\hline$>20 \%$ in enrolled patients / patients with invasive NTS infection & $17(65)$ & Assessed before introduction of revised breakpoints & $20(53)$ \\
\hline Number of screened cultures & $n=53$ & Assessment of fluoroquinolone non-susceptibility & 38 \\
\hline $0-99$ & $5(9)$ & Only nalidixic acid resistance reported & $1(3)$ \\
\hline $100-499$ & $10(19)$ & Only ciprofloxacin resistance reported & $25(66)$ \\
\hline $500-999$ & $9(17)$ & Nalidixic acid and ciprofloxacin resistance reported & $11(29)$ \\
\hline $1000-5000$ & $12(23)$ & Pefloxacin resistance reported & $1(3)$ \\
\hline$>5000$ & $17(32)$ & & \\
\hline
\end{tabular}

NTS non-typhoidal Salmonella, CSF cerebrospinal fluid, AST antibiotic susceptibility testing, CLSI Clinical and Laboratory Standards Institute, EUCAST European Committee on Antimicrobial Susceptibility Testing, BSAC British Society of Antimicrobial Chemotherapy

A meta-analysis revealed a modest increase in the pooled proportion of C3G-resistant NTS after 2010 up to 5\% (Fig. 5). After exclusion of grade D studies in the sensitivity analysis, the pooled proportion after 2010 was $1 \%$ (95\% confidence interval (CI), $0-4 \%$ ) and did not indicate an increase (Additional File 1: Figure S5). Overall the pooled proportions of C3G resistance were similar in Salmonella Typhimurium and Salmonella Enteritidis (Additional File 1: Figure S6B), although local differences occurred $[34,56,58,70]$. Meta-regression only identified the study period as a significant moderator (Additional File 1: Table S7). The emergence of C3G 


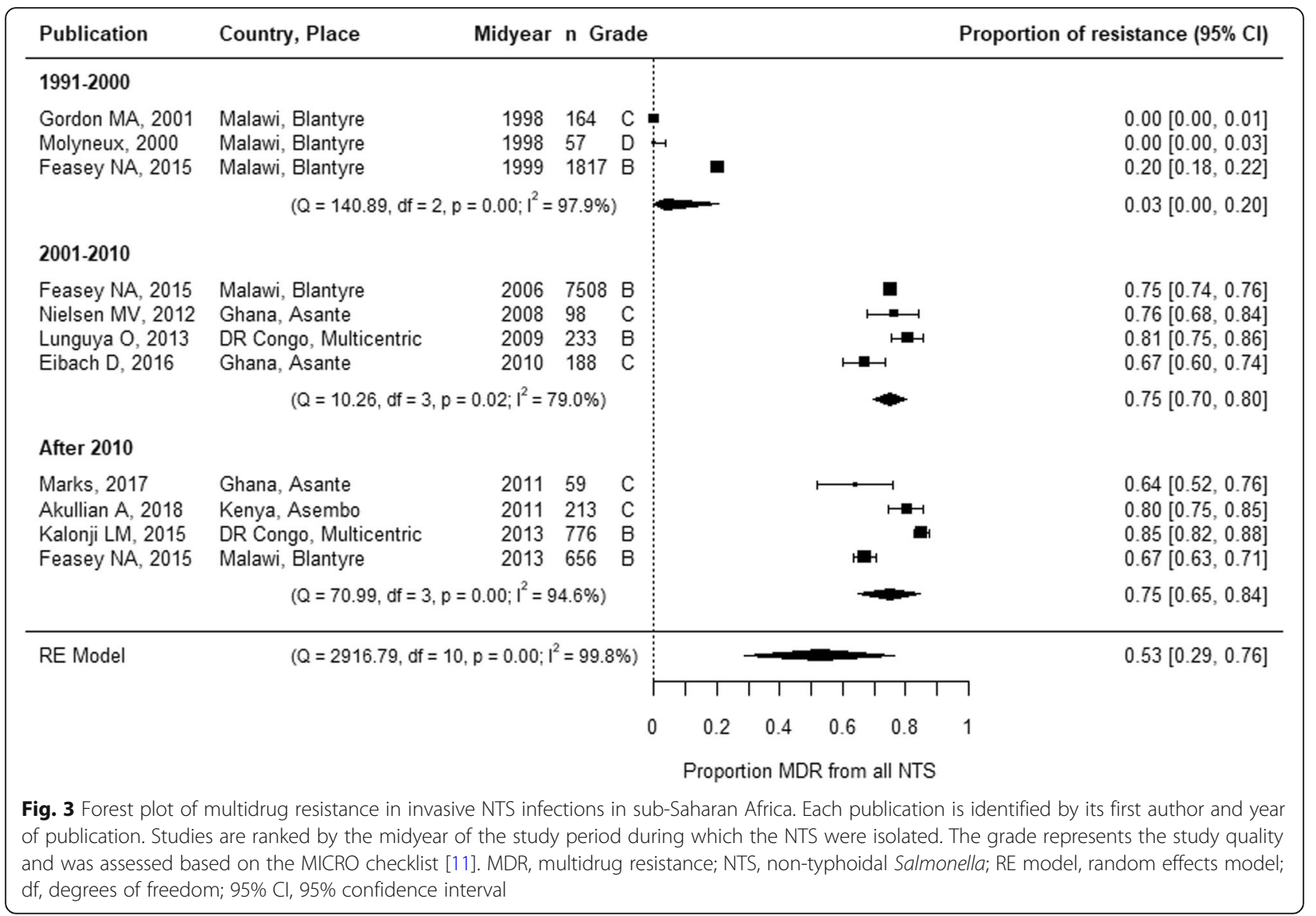

resistance was reported in all four sub-Saharan African regions since 2001 (Fig. 4).

\section{Fluoroquinolone non-susceptibility}

Before 2001, FQNS was first reported in NTS obtained from Rwanda between 1982 and 1987. These NTS were nalidixic acid resistant, but ofloxacin and norfloxacin susceptible; ciprofloxacin was not tested [32]. FQNS in NTS was found in one other study (Kenya, isolates obtained between 1997 and 2000). These NTS $(n=14)$ were probably DCS, as they were nalidixic acid resistant but ciprofloxacin susceptible according to the old breakpoints [48]. All other studies reported 100\% fluoroquinolone susceptibility: one study tested nalidixic acid [51], eight tested ciprofloxacin [36, 46, 47, 50, 52-54, 59], one pefloxacin [31], and two ofloxacin [30, 45].

After 2000, 36 studies reported ciprofloxacin susceptibility data [29, 33-42, 46-48, 50-54, 56-69, 71-73], and 11 of them also reported on nalidixic acid susceptibility $[35,38,42,48,51,61,65-67,72]$. Ten studies reported FQNS isolates without differentiation between DCS and FQR, although they were published after the revision of the ciprofloxacin breakpoints in 2012 [33, 37, 40, 56, 57, 59, 60, 62, 68, 69]. From the eight studies that defined
DCS [34-36, 39, 41, 42, 58, 61], DCS NTS were observed in six studies (DR Congo, Burkina Faso, Ghana, South Africa, and Ethiopia) [34, 35, 41, 42, 58, 61]. FQR was sporadically observed in Nigeria, DR Congo, Kenya, Ethiopia, Malawi, and South Africa [36, 38, 58, 61, 66, $71,72]$. Both DCS and FQR were observed in South Africa and Ethiopia. In South Africa, there was more DCS $(26 \%, n=1137)$ than FQR $(2 \%, n=86)$ [58]. In Ethiopia, FQR (4/17 NTS) was more prevalent than DCS $(1 / 17)$, although the reported $10 / 17$ nalidixic acidresistant isolates suggested more FQNS NTS [61]. Nalidixic acid resistance also suggested DCS NTS in Kenya, DR Congo, and Mozambique [38, 48, 65, 72]. However, in another study in Mozambique, nalidixic acid only detected 1/4 FQNS NTS [67].

Meta-analysis showed the emergence of FQNS, but there was no clear increase in pooled proportions of FQNS over time (Fig. 6). Similar results were obtained if grade D studies were excluded. However, when studies with < 50 NTS were not excluded in the sensitivity analysis, the pooled proportions increased, albeit nonsignificantly, from $0.1 \%$ (95\% CI, $0-1.3 \%$ ) in the period $1991-2000$ to $2.8 \%$ (95\% CI, $0.9-5.6 \%$ ) in $2001-2010$ and 3.6\% (95\% CI, 0.2-9.6\%) after 2010 (Additional File 1: 


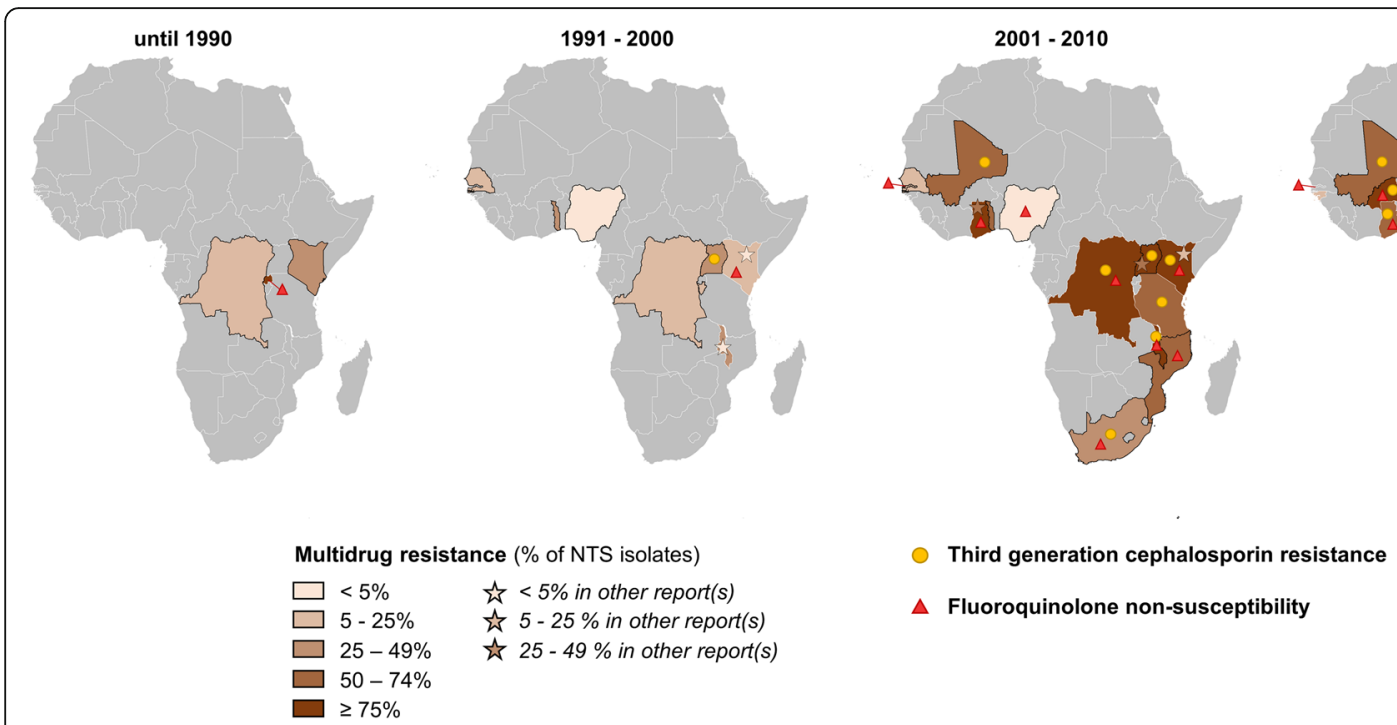

Fig. 4 Spatiotemporal overview of the emergence of multidrug resistance, third-generation cephalosporin resistance, and fluoroquinolone nonsusceptibility in invasive NTS infections in sub-Saharan Africa. The proportions of multidrug-resistant NTS per time period per country were represented by the choropleth. The presence of third-generation cephalosporin resistance or fluoroquinolone non-susceptibility was indicated with a circle or a star, respectively. For countries represented with black boundaries, the maximum proportion of multidrug-resistant NTS was plotted as no data on multidrug resistance were reported. The maximum proportion of multidrug-resistant NTS was determined as the lowest proportion among ampicillin, trimethoprim-sulfamethoxazole, and chloramphenicol resistance. For the sub-Saharan African countries in gray, no data were available. From 2001 to 2010, the maximum proportion of multidrug resistance in The Gambia was 19.4\%, which is not clearly visible due to the small size of the country. For Rwanda in the period until 1990 and for The Gambia in the periods 2001-2010 and after 2010, the triangle indicating the presence of fluoroquinolone non-susceptibility is displayed right next to the respective country and connected to it with a thin line due to the small country sizes. NTS, non-typhoidal Salmonella

Figure S5). The emergence of FQNS was similar in Salmonella Typhimurium and Salmonella Enteritidis (Additional File 1: Figure S6C). No significant moderators were identified by meta-regression (Additional File 1: Table S7). FQNS NTS were reported from all four subSaharan African regions in the last two decades (Fig. 4).

\section{Susceptibility to alternative antibiotics}

Three studies reported azithromycin susceptibility, which was interpreted according to the epidemiological cutoff for Salmonella Typhi (MIC > $16 \mathrm{mg} / \mathrm{l}$ ). Two of them reported on DR Congo were azithromycin resistance that was found in $3.3 \%(n=6)$ of Salmonella Typhimurium between 2007 and 2010 and in 12.7\% $(n=49)$ of Salmonella Typhimurium between 2011 and 2015. There was no azithromycin resistance in Salmonella Enteritidis [34, 35]. In Burkina Faso, no azithromycin resistance was observed [42]. None of the four studies that reported carbapenem susceptibility detected carbapenem-resistant isolates [34, 40, 49, 57]. Two studies reported $100 \%$ aztreonam susceptibility $[32,53]$, and one study, $100 \%$ colistin susceptibility [66]. Multiple studies reported susceptibility data for antibiotics which are ineffective in vivo, i.e., first- or second-generation cephalosporins $(n=12)$, aminoglycosides $(n=28)$, or tetracyclines $(n=24)$ (Additional File 2).

\section{Combined resistance patterns}

Two studies from DR Congo reported NTS that were MDR and DCS or MDR and C3G-resistant (ESBL). MDR in combination with DCS was found in eight Salmonella Typhimurium from 2007 to 2010 [35] and in seven Salmonella Typhimurium and two Salmonella Enteritidis from 2011 to 2014 [34]. MDR and ESBL combined were found in 45 Salmonella Typhimurium, from which 44 were also azithromycin resistant [34]. One Salmonella Typhimurium was MDR, DCS, ESBL, and azithromycin resistant [35].

\section{Evidence and recommendations on antimicrobial therapy in invasive NTS infections Study characteristics}

We identified 16 primary research studies with data on antimicrobial treatment efficacy, all were noninterventional and appraised as low quality (Fig. 2). Nine of them were conducted in sub-Saharan Africa $[32,43,74-80]$. Five studies had a comparative design, comparing two different treatment regimens $(n=1)$, different durations of antimicrobial treatment $(n=2)$, and cefotaxime versus no cefotaxime $(n=2)$ (Table 2) [32, 77, 80, 87, 88]. None of the studies assessed the duration of fecal carriage. 
Forest Plot of C3G-resistance prevalence

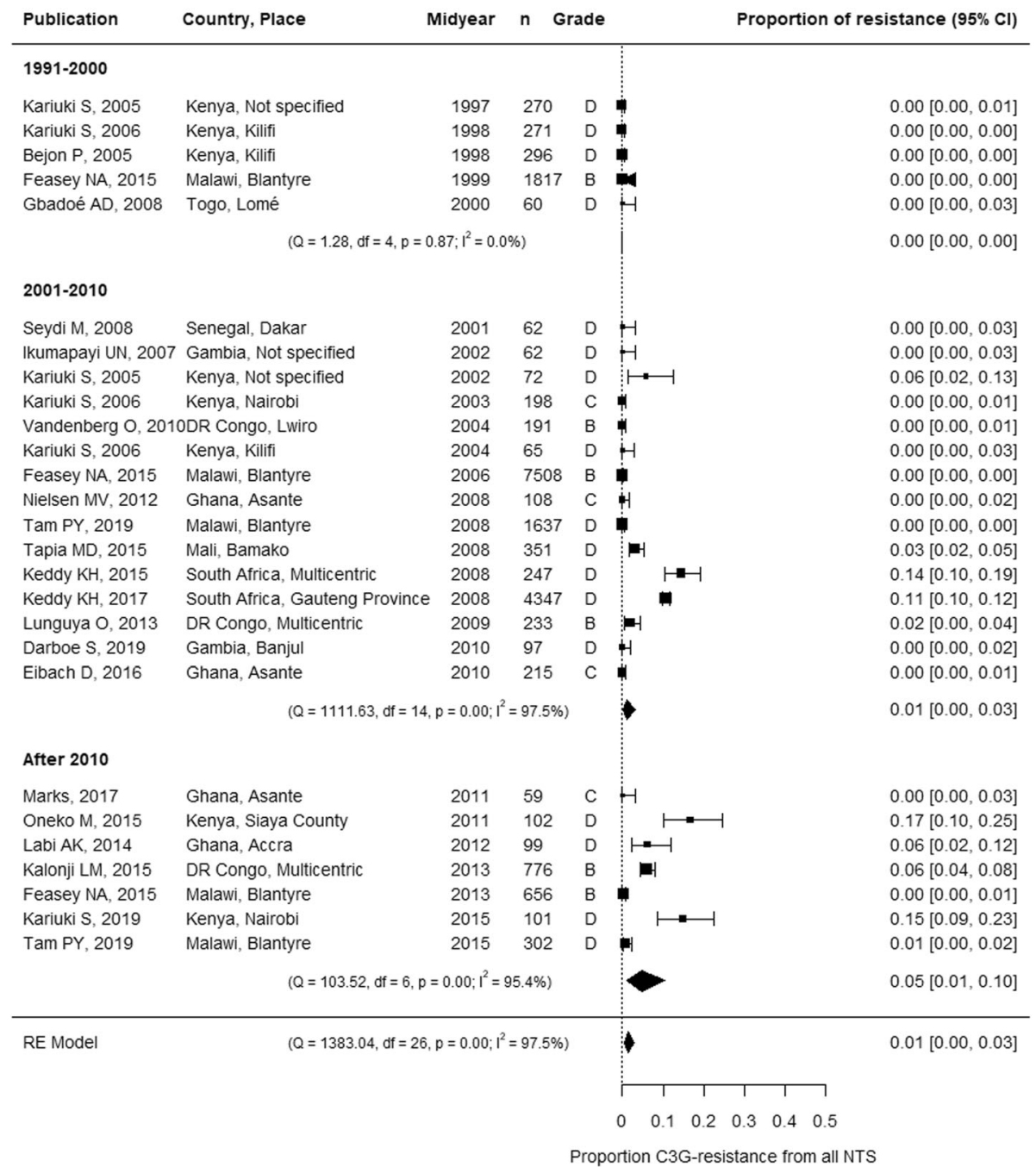

Fig. 5 Forest plot of third-generation cephalosporin resistance in invasive NTS infections in sub-Saharan Africa. Each publication is identified by its first author and year of publication. Studies are ranked by the midyear of the study period during which the NTS were isolated. The grade represents the study quality and was assessed based on the MICRO checklist [11]. C3G resistance, third-generation cephalosporin resistance; NTS, non-typhoidal Salmonella; RE model, random effects model; df, degrees of freedom; 95\% Cl, 95\% confidence interval

From the 36 publications with recommendations on antimicrobial treatment, six were national guidelines (Table 3) [97, 98, 108, 112, 115, 119]. The remaining 30 publications were expert opinion papers $(n=3)[105,113$, 114], narrative reviews $(n=26)[5,6,75,89-96,99-104$, 109-112, 116-118, 120], and a systematic review [121]. One paper reported primary research data and formulated treatment recommendations after an extensive literature review [83]. Sixteen publications based their recommendations on observational or case studies, 16 publications referred to other reviews or guidelines, and four publications referred to the evidence available for enteric fever. Twelve papers with treatment recommendations did not refer to any published evidence in humans (Table 3). We appraised 21 publications as low quality and 15 as moderate quality (Additional File 3).

\section{Evidence on antimicrobial treatment efficacy and safety}

Table 2 gives a detailed overview of the population, antimicrobial treatment regimens, and outcomes per included study. Large differences in study population and setting might affect the observed treatment outcome, e.g., the in-hospital case fatality for intravenous chloramphenicol treatment was higher in children with meningitis (49\%) [43] than in children with bloodstream infection (24\%) [81] and higher in cohorts of patients with HIV [76]. In HIV, high recurrence rates (43\%) were seen after 14 days of chloramphenicol [76]. In $85 \%$ of 
Forest Plot of FQNS prevalence

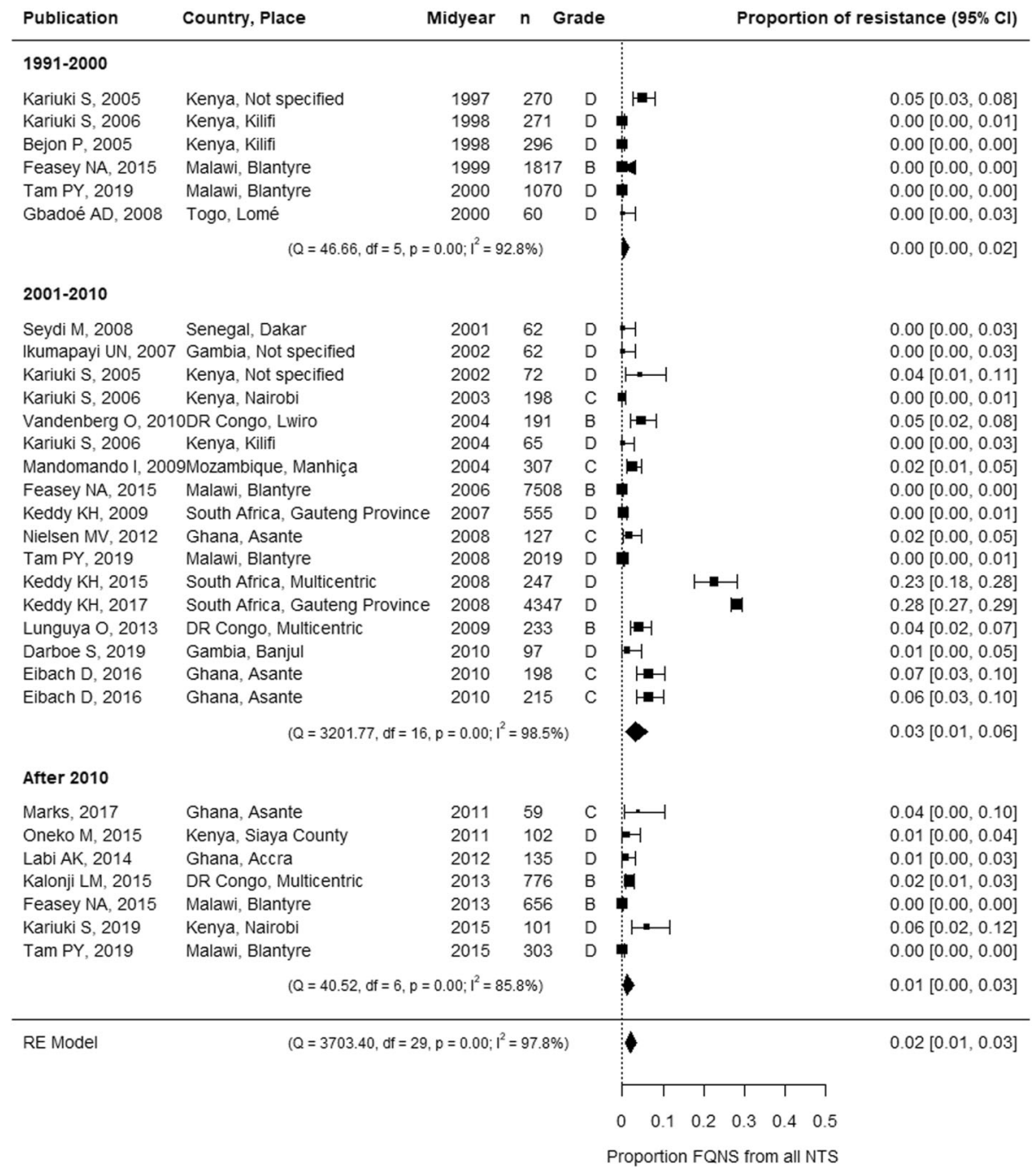

Fig. 6 Forest plot of fluoroquinolone non-susceptibility in invasive NTS infections in sub-Saharan Africa. Each publication is identified by its first author and year of publication. Studies are ranked by the midyear of the study period during which the NTS were isolated. The grade represents the study quality and was assessed based on the MICRO checklist [1 1]. FQNS, fluoroquinolone non-susceptibility; NTS, non-typhoidal Salmonella; RE model, random effects model; df, degrees of freedom; 95\% Cl, 95\% confidence interval

patients with HIV and bloodstream infection, fever resolved within $72 \mathrm{~h}$ with chloramphenicol [74].

With C3G, fever often resolved within 3 days [77, 83]. In Rwandan children from whom 220/246 had a bloodstream infection, cefotaxime treatment resulted in an inhospital case fatality of $11 \%$, compared to $74 \%$ in children who did not receive cefotaxime. However, the latter group included children that died before the blood culture results were available, which introduced a large bias in the study results [32]. Recurrence rates were low after C3G treatment (Table 2) [83, 84]. However, a high proportion of persistent bacteremia (4/11) was seen in cefamandole regimens, a first-generation cephalosporin, despite in vitro susceptibility [82].
In fluoroquinolone-based treatment regimens, case fatality ratios varied between 3 and 14\% (Table 2). Recurrences were often seen in patients with $\operatorname{HIV}[79,86]$ but did not occur in children from DR Congo [78]. In the latter study, microbiological clearance occurred within $48-72 \mathrm{~h}$ after the start of oral ciprofloxacin treatment in all children, and possible fluoroquinolone side effects were observed in $3 / 36$ children, i.e., one child with sickle cell anemia had increased bilirubin measurements, one child had raised aminotransferase enzymes that resolved upon the termination of ciprofloxacin, and one child had a swollen knee that resolved within $48 \mathrm{~h}$. In none of them, ciprofloxacin treatment was interrupted earlier [78]. 
Table 2 Table summarizing the evidence on the efficacy of antimicrobial treatment in invasive non-typhoidal Salmonella infections

\begin{tabular}{|c|c|c|}
\hline $\begin{array}{l}\text { Study (first author, year } \\
\text { of publication, study site, } \\
\text { study period, study design) }\end{array}$ & $\begin{array}{l}\text { Population (age category, } \\
\text { sample size, infection site, } \\
\text { comorbidities) }\end{array}$ & $\begin{array}{l}\text { Therapy (antibiotic agent, dose, } \\
\text { administration route, duration, } \\
\text { control/comparison group) }\end{array}$ \\
\hline
\end{tabular}

Outcome (in-hospital and

post-discharge case fatality, fever clearance, microbiological clearance, recurrence, sequelae)

Chloramphenicol

Aubry, 1992 [74], 1991,

Burundi, retrospective

cohort study

Molyneux, 2000 [43],

Malawi, 1996-1999,

prospective cohort

study

Adults, $n=69$, all BSI, HIV

positivity in $86 / 103$ (83\%)

Children, $n=57$, all

meningitis, clinical

suspicion of AIDS in 16\%

Graham, 2000 [81],

Malawi, 1996-1998,

retrospective cohort

study

Gordon, 2003 [76]

Malawi, period not

specified, prospective

cohort study

\section{Cephalosporins}

De Carvalho, 1982 [82], setting and period not specified, prospective cohort study

Soe, 1987 [83], the USA, period not specified, retrospective cohort study

Lepage, 1990 [32], Rwanda, 1982-1987, retrospective cohort study

Wang, 1996 [84],

Taiwan, 1990-1994,

case series

Chiu, 2006 [85], Taiwan,

1999-2003,

retrospective cohort

study

Fluoroquinolones

Cheesbrough, 1991

[78], DR Congo, period

not specified,

prospective cohort

study

Forrest, 2009 [86], USA, 2002-2006,

retrospective cohort

study

Children, $n=248$, all BSI, clinical suspicion of AIDS in $16 \%$

Adults, $n=100$, all BSI, all HIV patients

Children and adults, $n=11$, all BS

Children and adults, $n=12,9$ BSI, 2 meningitis, disease in $1 / 12$, AIDS in $1 / 12$, leukemia in $1 / 12$

Children, $n=246,220$ BSI,

12 meningitis, 13 focal infections, severe acute malnutrition in 23\%, malaria in $11 \%$, severe anemia in $10 \%$

Adults (> 65 years), $n=12$, all mycotic aneurysms

Children, $n=27$, all BSI

Children, $n=31,29 \mathrm{BSI}$, 4 arthritis (including 2 with $\mathrm{BSI})$

Adults, $n=16$, all BSI, all HIV patients
Chloramphenicol

Chloramphenicol IV until defervescence and able to swallow, then PO and stop after 2-3 weeks oral treatment

Chloramphenicol $2 \mathrm{~g} /$ day in 4 doses/day for 14 days 1 focal infection, sickle cell
Cefamandole IV/IM 60-240 mg/kg/day for 12 days (longer if persistent bacteremia)

Cefotaxime IV in $9 / 12$ for $5-28$ days Adults: 2-3 g/day in 3-6 doses/day Children: $100-200 \mathrm{mg} / \mathrm{kg} /$ day in 4 doses/day

Ceftizoxime IV in 1/12 for 19 days

Cefotaxime IV 2 days + change to ceftazidime IV 14 days in $1 / 12$

Cefotaxime IV 2 days + change to cotrimoxazole $\mathrm{PO} 3$ days in $1 / 12$

Cefotaxime IV $100 \mathrm{mg} / \mathrm{kg} /$ day (200 mg/kg/day if meningitis) for 8 days to 6 weeks (depending on the infection site and severity)

Control group ( $n=87 / 246)$ : no cefotaxime because no cefotaxime available/death before blood culture results

Ceftriaxone (+ surgical intervention in $11 / 12$ patients) for $23-40$ days in survivors

Ceftriaxone IV in 25/27; cefixime PO in $2 / 27$

Ciprofloxacin PO $20 \mathrm{mg} / \mathrm{kg} /$ day in 2 doses/day

Quinolones in 15/16 patients for 10-300 days (median 28 days)
Fever clearance in $72 \mathrm{~h}$ : $59 / 69(85 \%)$

In-hospital case fatality: 28/57 (49\%)

Post-discharge case fatality: 5/29 (17\%)

Recurrences: 2/29 (7\%)

In-hospital case fatality: $59 / 248(23.8 \%)$

In-hospital case fatality: 47/100 (47\%)

Post-discharge case fatality: 5/19 (26\%)

Recurrence: 19/44 (43\%)

Persistent bacteremia after 12 days: 4/11 (36\%)

In-hospital case fatality: 0/12 (0\%)

Fever clearance: median 3 days (range 1-17 days)

Recurrences: 1/12 (8\%)

In-hospital case fatality: 16/152 (11\%)

Recurrence: $4 \%$ of NTS BSI

Fever clearance: mean 2.3 days (range $0.5-7.5$ days)*

Control group: in-hospital case fatality 64/87 (74\%)

In-hospital case fatality: 6/12 (50\%)

Recurrence: 0/6 (0\%)

In-hospital case fatality: 1/27 (4\%): a leukemic patient with spondylitis and splenic abscess treated with ceftriaxone

In-hospital case fatality: 1/31 (3\%)

Post-discharge case fatality: 0/30 (0\%)

Microbiological clearance after 48-72 h: 0/30 (0\%)

Recurrence: 0/30 (0\%)

In-hospital case fatality: 1/15 (7\%)

Recurrences: 4/15 (27\%) 
Table 2 Table summarizing the evidence on the efficacy of antimicrobial treatment in invasive non-typhoidal Salmonella infections (Continued)

\begin{tabular}{|c|c|c|}
\hline $\begin{array}{l}\text { Study (first author, year } \\
\text { of publication, study site, } \\
\text { study period, study design) }\end{array}$ & $\begin{array}{l}\text { Population (age category, } \\
\text { sample size, infection site, } \\
\text { comorbidities) }\end{array}$ & $\begin{array}{l}\text { Therapy (antibiotic agent, dose, } \\
\text { administration route, duration, } \\
\text { control/comparison group) }\end{array}$ \\
\hline $\begin{array}{l}\text { Gordon, } 2010[79], \\
\text { Malawi, period not } \\
\text { specified, prospective } \\
\text { cohort study }\end{array}$ & \multirow[t]{2}{*}{ Adults, $n=70$, all BSI, all HIV patients } & $\begin{array}{l}\text { Ciprofloxacin PO } 1 \mathrm{~g} / \text { day, in } \\
2 \text { doses/day } 10 \text { days (started after NTS } \\
\text { isolation from blood culture) }\end{array}$ \\
\hline $\begin{array}{l}\text { Epidemiological comparison } \\
\text { between regimens }\end{array}$ & & \\
\hline $\begin{array}{l}\text { Molyneux, } 2009 \text { [80], } \\
\text { Malawi, 1997-2006, } \\
\text { retrospective cohort } \\
\text { study }\end{array}$ & $\begin{array}{l}\text { Children, } n=105 \text {, all } \\
\text { meningitis HIV positivity } \\
\text { in } 49 / 105(47 \%)\end{array}$ & $\begin{array}{l}\text { 1997-2001: } \\
\text { Chloramphenicol IV } 100 \mathrm{mg} / \mathrm{kg} / \text { day } \\
\text { in } 4 \text { doses/day for } 14 \text { days in } 21 / 29 \\
\text { Ceftriaxone IV } 100 \mathrm{mg} / \mathrm{kg} / \text { day in } \\
2 \text { doses/day for } 10 \text { days in } 8 / 29 \\
\text { 2002-2006: } \\
\text { Ceftriaxone IV } 100 \mathrm{mg} / \mathrm{kg} / \text { day in } \\
2 \text { doses/day for } 10 \text { days } \\
\text { (76/76) + ciprofloxacin PO } \\
20 \mathrm{mg} / \mathrm{kg} / \text { day in } 2 \text { doses/day for } \\
14 \text { days (76/76) }\end{array}$ \\
\hline
\end{tabular}

Antimicrobial treatment duration

Tsai, 2007 [87], Taiwan,

1996-2003,

retrospective cohort

study
Hess, 2019 [88], USA, 2007-2016, retrospective cohort study

\section{Children, $n=184$, all BSI}

Children, $n=51$, all BSI

\author{
Group $<7$ days: \\ Median 5 days antimicrobial \\ treatment \\ Ceftriaxone/cefotaxime in 31/49, \\ ampicillin in 16/49, other in 2/49 \\ Group $\geq 7$ days \\ Median 9.5 days antimicrobial \\ treatment \\ Ceftriaxone/cefotaxime in 121/135, \\ ampicillin in 14/135 \\ Initial treatment: \\ Ceftriaxone/cefotaxime IV in 48/51, \\ others in 3/51 \\ Group $<7$ days IV treatment \\ Median 4 days IV treatment \\ Switch to amoxicillin, cotrimoxazole, \\ third-generation cephalosporins or \\ ciprofloxacin after $<7$ days \\ Group $\geq 7$ days IV treatment \\ Median 9 days IV treatment \\ Switch to amoxicillin, cotrimoxazole, \\ third-generation cephalosporins or \\ ciprofloxacin after $\geq 7$ days or 10 days \\ ceftriaxone/cefotaxime IV
}

Outcome (in-hospital and post-discharge case fatality, fever clearance, microbiological clearance, recurrence, sequelae)

Total case fatality after

1 month: 10/70 (14\%)

Recurrence: 63/70 (90\%)

$$
\begin{aligned}
& \text { In-hospital case fatality: } \\
& \text { 1997-2001: 14/29 (48.2\%) } \\
& \text { 2002-2006: 41/76 (53.9\%) } \\
& \text { Post-discharge case fatality: } \\
& \text { 1997-2001: 3/29 (10.3\%) } \\
& \text { 2002-2006: 4/76 (5.3\%) } \\
& \text { Recurrences: } \\
& \text { 1997-2001: 9/15 (60\%), } \\
& \text { from which } 7 \text { HIV+ } \\
& \text { 2002-2006: } 3 / 35 \text { (8.6\%), } \\
& \text { from which } 1 \text { HIV+ } \\
& \text { Sequelae: } \\
& \text { 1997-2001: 11/12 (91.7\%) } \\
& \text { 2002-2006: 13/31 (41.9\%) }
\end{aligned}
$$

\author{
In-hospital case fatality: \\ 0/184 (0\%) \\ Post-discharge case fatality: \\ 0/184 (0\%) \\ Recurrences: 0/184 (0\%) \\ Persistent bacteremia: \\ Group < 7 days: 1/21 (5\%) \\ Group $\geq 7$ days: 1/43 (2\%)
}

Recurrences: 30-day readmission / emergency visit: Group < 7 days IV treatment: $0 / 32(0 \%)$

Group $\geq 7$ days IV treatment: $1 / 19$ (5\%)

Persistent bacteremia: Group $<7$ days IV treatment: $7 / 32(53 \%)$

Group $\geq 7$ days IV treatment: 9/19 (47\%)

$B S I$ bloodstream infection, $P O$ per os, $I V$ intravenous, $h$ hours

*One study was a study on a subgroup [77] from another included study [32]. As data on fever clearance were only reported in the subgroup study [77], the fever clearance data were taken into account and the other data from the subgroup study were disregarded

A study in Malawian children with meningitis compared the clinical outcome of two different treatment regimens epidemiologically. During the 5 years that ceftriaxone followed by fluoroquinolones was the standard treatment, the in-hospital case fatality was similar, but less fatal cases after discharge, less recurrences, and less sequelae occurred (Table 2) [80]. In children with bloodstream infection, a study in Taiwan compared a total antimicrobial treatment duration of $<7$ days with one of $\geq 7$ days [87], and a study in the USA compared $<7$ days intravenous antimicrobial treatment with $\geq 7$ days of intravenous antimicrobials [88]. They reported similar outcomes in both groups with the exception of slightly higher proportions of persistent bacteremia in the $<7$ days groups (Table 2). It was however not clear at which treatment day the repeat blood cultures were taken. 


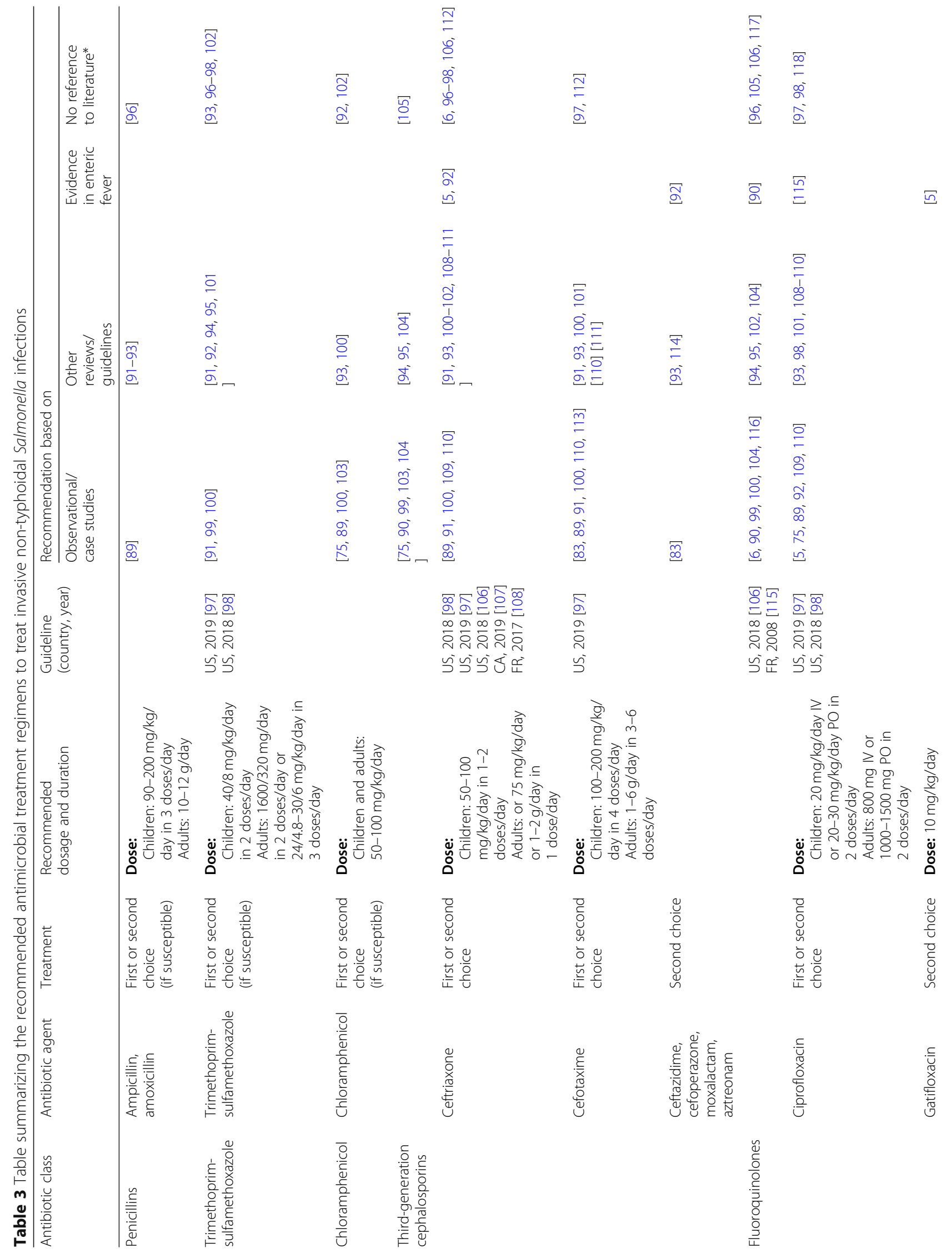




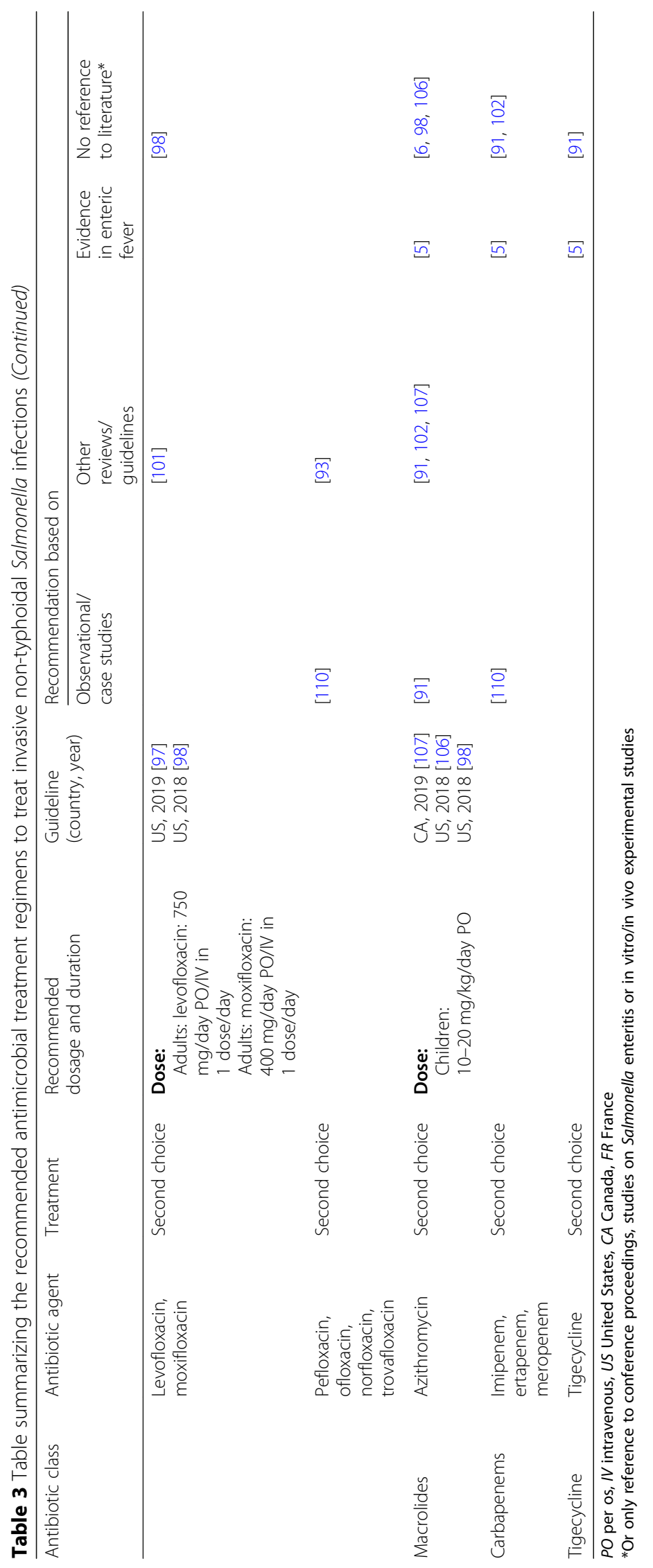




\section{Recommendations on antimicrobial treatment of invasive NTS infections}

To treat invasive NTS infections, both the "Access group" antibiotics ampicillin, trimethoprim-sulfamethoxazole, and chloramphenicol, and C3G (ceftriaxone or cefotaxime) or fluoroquinolones (ciprofloxacin) from the "Watch group" antibiotics were often recommended as the first-choice antibiotics (Table 3). Some of these antibiotics were sporadically considered as the second choice due to the high prevalence of resistance, intolerance, safety concerns, or lack of treatment efficacy data (Additional File 2).

Some authors had concerns about the use of chloramphenicol to treat invasive NTS infections due to a possible lack of bactericidal activity [92, 99], high relapse rates [92, 93], no effect on carrier states [92, 93], and the need for long treatment courses [93]. In focal infections (osteomyelitis and endovascular infections), clinical failure was mentioned $[89,100]$. In NTS meningitis, poor clinical efficacy and prolonged culture positivity of the cerebrospinal fluid were mentioned [99, 122]. Finally, some authors cited chloramphenicol safety issues, i.e., bone marrow depression and hepatic toxicity $[92,93,99]$.

The need for clinical efficacy data and clinical trials on fluoroquinolones and C3G was already stated in 1986 and 1988 [95, 122]. For fluoroquinolones, the most frequent adverse events would be mild to moderate, reversible, gastrointestinal, dermatological, or neurological disturbances. The potential joint toxicity or cartilage destruction, particularly in children, was based on animal studies, from which the relevance in humans remains unclear [99, 116]. In addition, authors warranted that the use of fluoroquinolones to treat NTS could promote resistance in tuberculosis [6]. Thirdly, fluoroquinolones should not be used when resistance to nalidixic acid or decreased ciprofloxacin susceptibility is observed due to the risk of treatment failure [98, 109, 114, 115]. Finally, contradictory statements were made on the efficacy of fluoroquinolones in meningitis $[91,110]$ and the added value of combining C3G with fluoroquinolones (Additional File 2) [90, 91, 114].

Fluoroquinolones other than ciprofloxacin and C3G other than ceftriaxone and cefotaxime were generally listed as second-choice antimicrobial treatment options (Table 3). The use of azithromycin as a second-choice antibiotic was recommended in various publications, including the Red Book, the Sanford Guide to Antimicrobial Therapy, and the Canadian National Guidelines (Table 3). The need for studies on azithromycin use in NTS infections was explicitly stated in 2004 [114].

The recommendation for the duration of antimicrobial treatment differed according to the site of infection. For bloodstream infections, oral or intravenous antibiotic courses of 7-14 days were generally recommended [5, 89-91, 94, 97, 98, 101, 104, 106, 110-115, 121], although for azithromycin, 5-7 days would be sufficient [5, 91, 107]. For bloodstream infections in HIV patients with $<200 \mathrm{CD} 4$ cells $/ \mathrm{mm}^{2}, 2-6$ weeks of antibiotics were recommended [97, 109, 123]. For meningitis, 3-6 weeks antibiotic courses were recommended [89, 91, 99, 100, 103, 106, 109-111]. For osteomyelitis and other focal infections, 4-6 weeks of antibiotics were generally recommended $[89,91,95,106,111,112]$, although 2-4 weeks of fluoroquinolones or C3G were also suggested [114]. Finally, for (possible) endovascular infections, antibiotic courses of 4-6 weeks or even longer were recommended [90, 94, 95, 98, 114].

The use of oral fluoroquinolones to treat invasive NTS infections was recommended in various publications, including the Red Book, the Sanford Guide, and the NIH guidelines on opportunistic infections in patients with AIDS [97, 98, 106, 108, 110, 116]. The Red Book suggested that to treat bloodstream infections, intravenous ceftriaxone can be switched to oral fluoroquinolones or azithromycin when the blood culture is cleared and focal infections are excluded [106]. Sequential intravenous and oral treatment in children over 12 months with bloodstream infection was also recommended in a review [91]. In the treatment of a first bloodstream infection in patients with AIDS, 1-2 weeks of intravenous antibiotics could be continued for 4 weeks with an oral fluoroquinolone [114]. To treat osteomyelitis, intravenous antibiotics could be switched to oral antibiotics if systemic symptoms resolved [110].

\section{Discussion}

\section{Summary of findings}

This systematic review and meta-analysis provides a spatiotemporal overview of AMR in invasive NTS infections in sub-Saharan Africa and an extensive overview of all available evidence and recommendations on its antimicrobial treatment. Since 2001, MDR was observed in more than half of the NTS isolates in almost all subSaharan African countries. In addition, we report the presence of C3G resistance and FQNS in all four subSaharan African regions. The meta-analysis revealed an increase in the pooled proportion of C3G resistance up to 5\% resistant isolates after 2010. The emergence of FQNS was more variable and was not reflected in increasing pooled proportions over time. Nevertheless, the presence of $>5 \%$ FQNS was reported in South Africa [56, 58], Ethiopia [61], Kenya [60], Mozambique [40, 67], Ghana [41, 68], and Burkina Faso [37]. Although no official breakpoints on azithromycin susceptibility exist yet, the presence of azithromycin-resistant NTS was suggested in DR Congo. Full carbapenem susceptibility was observed in the few studies that reported on carbapenems. Susceptibility data for first- or second-generation cephalosporins or aminoglycosides were often reported. 
These antibiotics are included in routine antibiotic susceptibility testing panels for Enterobacterales, and in the daily practice of a diagnostic laboratory, they are inoculated together with the identification test, i.e., before the identification of Salmonella. However, CLSI warns not to report Salmonella as susceptible to these antibiotics due to in vivo inefficacy [124]. Likewise, tetracycline susceptibility was often reported. Tetracycline is not included in the routine antibiotic susceptibility testing panel for Enterobacterales and is clinically irrelevant $[125,126]$, but is monitored for epidemiological purposes, in particular within the scope of foodborne and zoonotic salmonellosis $[127,128]$.

As expected, this review did not find high-quality evidence on the efficacy or safety of antimicrobial treatment of invasive NTS infections. No data were available from interventional or dedicated observational clinical studies. In analogy with the lack of evidence, we did not find supranational guidelines on the antimicrobial treatment of invasive NTS infections. However, we found three guidelines from the USA that are used internationally, i.e., the Red Book, the Sanford Guide to Antimicrobial Therapy, and the NIH guidelines on the prevention and treatment of opportunistic infections in patients with AIDS [97, 98, 106]. In general, the "Access group" antibiotics ampicillin, trimethoprim-sulfamethoxazole, and chloramphenicol and the "Watch group" antibiotics ceftriaxone, cefotaxime, and ciprofloxacin were recommended as the first-choice antibiotics. Some also recommended the use of the "Watch group" antibiotic azithromycin [7]. Most authors proposed 7-14 days of antibiotics for uncomplicated bloodstream infections and 4-6 weeks for meningitis, osteomyelitis, endovascular, or other focal infections. The possibility of oral antimicrobial treatment or switch to oral antimicrobial treatment was suggested in some guidelines and reviews.

\section{Limitations}

This review had some limitations. Firstly, we had to exclude studies that did not report separate data for Salmonella (Para) Typhi and NTS or invasive and intestinal infections. As such, we may have missed some data on AMR and treatment. We could include only four studies that reported susceptibility data from NTS isolated before 1991, and from some sub-Saharan African countries, we could not include a single study. In addition, the temporal resolution was affected by compiled antibiotic susceptibility data from studies that reported in long time periods. Moreover, only nine from the 16 treatment efficacy studies reported data from subSaharan Africa. As the Salmonella Typhimurium and Enteritidis strains circulating in sub-Saharan Africa have a more invasive genotype and phenotype, data from NTS causing invasive infections in high-risk patients or transient bacteremia in other settings may not be generalizable to invasive NTS infections in sub-Saharan Africa.

Secondly, it is likely that publication and reporting bias favoring studies that reported resistant NTS occurred, particularly during the early years. However, MDR and FQNS will also have been underreported. The definition of MDR is a recent convention [5, 23, 24], and the first study that reported MDR was only published in 2012. Before the revised breakpoints in 2012, only FQR was detected $[18,19,25]$, but nalidixic acid resistance suggested the presence of DCS in six studies $[32,38,48,61$, 65, 72]. Even after the revision of the fluoroquinolone breakpoints, some studies did not clarify if DCS was taken into account while assessing FQNS.

Finally, a careful interpretation of the pooled proportions of MDR, C3G resistance, and FQNS is warranted. The heterogeneity was high in all meta-analyses. Although subgroup analysis per time period reduced the heterogeneity, the residual heterogeneity remained high. By meta-regression, we aimed to further reduce the heterogeneity, but we could not identify other study characteristics as effect moderators. It is however plausible that the study designs differed in too many aspects to identify the effect of specific characteristics. In addition, we decided to exclude the data from studies reporting susceptibility data for $<50$ NTS, although these studies might still be representative for their study population, and when these studies were included in the meta-analysis, a trend in increasing FQNS was observed. Finally, we excluded studies with a grade $E$ quality from the meta-analyses due to uncertainty or inconsistency in some of their reported data, while (most of) their data might be correct. By contrast, we included studies with a grade D quality in the meta-analysis, while the quality of these data cannot be fully assured neither.

\section{Comparison to other Salmonella infections}

This study is the first systematic review and meta-analysis on AMR and antimicrobial therapy in invasive NTS infections. While recently two systematic reviews have been published on the emergence of AMR in enteric fever [129, $130]$, this systematic review and meta-analysis finally provides data on the spatiotemporal distribution of AMR in invasive NTS infections across sub-Saharan Africa. The pooled proportion of MDR in NTS was comparable with the proportion of MDR in Salmonella Typhi in subSaharan Africa in these two reviews $[129,130]$. However, we observed more C3G resistance in NTS than in their data on Salmonella Typhi, while they reported more FQNS than our observations in NTS $[129,130]$. Another recent systematic review and meta-analysis assessed the presence of MDR and FQNS in Salmonella Typhi and 
non-typhi infections in sub-Saharan Africa, without differentiating between intestinal and invasive infections. They reported similar pooled MDR and FQNS proportions. They also reported more MDR in Salmonella Typhimurium than in Salmonella Enteritidis, but reported more FQNS in Salmonella Enteritidis than in Salmonella Typhimurium [131]. Finally, it is remarkable that treatment efficacy data and evidencebased supranational guidelines are widely available for intestinal Salmonella infections and enteric fever [5, $123,132-135]$, but are missing for invasive NTS infections which, in sub-Saharan Africa, have the highest disease burden of all three diseases $[1,2]$.

\section{Relevance and future implications}

The widespread presence of MDR and subsequent emergence of C3G resistance and FQNS in invasive NTS infections in sub-Saharan Africa seriously challenge treatment. Due to the high burden of invasive NTS infections in sub-Saharan Africa [2] and the frequency of NTS as the cause of invasive infections [4], this treatment challenge provokes a considerable public health threat. Firstly, the current empiric antimicrobial treatment guidelines for possible severe bacterial infections in African children do not cover invasive MDR NTS infections [3, 133]. Secondly, to allow treatment with any of the current first-choice antibiotic options for invasive NTS infections, the emergence of C3G resistance and FQNS must be contained. Therefore, the global action plan against antimicrobial resistance states the importance of consistent collection and monitoring of surveillance data to strengthen our knowledge [10]. In the current context of emerging C3G resistance and FQNS, clinicians will sometimes have to rely on second-choice antibiotics. Interpretative criteria for azithromycin susceptibility testing in NTS isolates from invasive infections are therefore urgently needed. In addition, susceptibility data on second-choice antibiotics like azithromycin and carbapenems should be tested and included in surveillance reports. In low-resource settings, ciprofloxacin MIC testing is technically challenging and pefloxacin and nalidixic acid disk tests are more feasible alternatives to test fluoroquinolone susceptibility [136]. Therefore, surveillance studies should report results from ciprofloxacin MIC testing and surrogate pefloxacin or nalidixic acid disk tests together. As such, the performance of pefloxacin and nalidixic acid surrogate disk tests in sub-Saharan Africa can be assessed. Moreover, in the context of emerging FQNS, it may be useful to test and report susceptibility to gatifloxacin, which can be an effective alternative to treat DCS NTS, as it is less affected by a common FQNS molecular mechanism (gyrA mutation). Gatifloxacin has been withdrawn from the market in many countries due to dysglycemia in elderly and diabetic patients, but this patient profile is uncommon in invasive NTS infections in subSaharan Africa [5]. Finally, the reporting of combined resistance patterns, e.g., MDR combined with C3G resistance and azithromycin resistance, should be promoted by the use of convened acronyms and definitions of extensive drug resistance (XDR) and pan drug resistance (PDR), as recently proposed by our research group [137]. These combined resistance patterns provide information about the antibiotic options left for treatment. The use of internationally convened definitions and acronyms will harmonize reporting and facilitate advocacy and policymaking.

Secondly, the global action plan against antimicrobial resistance highlights the need to optimize the use of antibiotics [10]. However, the current scarcity of data on antimicrobial treatment of invasive NTS infections hampers antibiotic stewardship in sub-Saharan Africa, where NTS are situated in the top three of pathogens causing bloodstream infections [4]. To formulate evidence-based supranational treatment guidelines for invasive NTS infections, interventional studies and dedicated observational studies must urgently be organized to provide data on treatment efficacy and safety. To align with the WHO essential medicines list, with the current antibiotic recommendations and the current clinical antibiotic use in sub-Saharan Africa, studies must initially focus on C3G, fluoroquinolones, and azithromycin. In addition, special attention must be given to an early switch to oral antibiotics. In general, the evidence supporting the superiority of intravenous antibiotic courses for invasive infections is weak. Moreover, early switch to oral antibiotics will shorten the hospital stay, reduce costs, and reduce healthcare-associated infections, which are of particular importance in a low-resource setting [121, 138-140].

Thirdly, and again in line with the global action plan against antimicrobial resistance, the emerging resistance in and the lack of data on the optimal treatment of invasive NTS infections highlight the need for preventive measures to decrease the disease incidence [10]. Currently, vaccines against NTS that cause invasive infections are being developed [141]. None of the treatment efficacy studies in this review assessed the impact of antibiotic treatment on the duration of fecal carriage, although it is known that antibiotics prolong fecal shedding in NTS gastroenteritis. In invasive NTS infections in sub-Saharan Africa, the role of fecal carriage has not been fully elucidated yet. However, increasing evidence supports a human instead of zoonotic transmission of invasive NTS in sub-Saharan Africa [63, 142] (Phoba M-F, Barbé B, Ley B, Van Puyvelde S, Post A, Mattheus W, et al.: High genetic similarity between non-typhoidal Salmonella isolated from paired blood and stool samples 
of children in the Democratic Republic of the Congo, accepted for publication). To design the appropriate public health interventions, more research that clarifies the transmission of the NTS strains circulating in sub-Saharan Africa is needed.

\section{Conclusion}

In this systematic review and meta-analysis, we demonstrated the widespread presence of MDR and the emergence of C3G resistance and FQNS in invasive NTS infections in all sub-Saharan African regions. In addition, we highlighted the lack of data on the efficacy and safety of antimicrobial treatment of these infections, which was reflected in the absence of supranational evidence-based guidelines. To contain the emergence of AMR in invasive NTS infections, close monitoring and harmonized reporting of surveillance data, including data on the presence of combined resistance patterns, are essential. Some of the current recommendations list azithromycin as a secondchoice antibiotic to treat invasive NTS infections. However, to allow its rational use, interpretative criteria for its susceptibility testing are needed. Lastly, clinical studies must be organized to provide the much needed data on the treatment efficacy of different antibiotic regimens, including regimens with early switch to oral administration. These data will finally allow the development of evidencebased and internationally harmonized guidelines and facilitate antibiotic stewardship.

\section{Supplementary information}

Supplementary information accompanies this paper at https://doi.org/10. 1186/s12916-020-01652-4.

Additional file 1: Table S1. Prisma checklist. List S2. Search strategy used for MEDLINE and Ovid Embase database searches. Table S3. Inand exclusion criteria for both research questions. List S4. Published articles from which no full text was found. Figure S5. Sensitivity analysis for multidrug resistance, third generation cephalosporins \& fluoroquinolone non-susceptibility. Figure S6. Meta-analysis and forest plots of multidrug resistance, third generation cephalosporin resistance and fluoroquinolone non-susceptibility according to NTS serotype. Table S7. Meta-regression to identify moderators of the pooled proportions of multidrug resistance (MDR), third generation cephalosporin resistance (C3G-resistance) and fluoroquinolone non-susceptibility (FQNS).

Additional file 2. Data extraction database and datasets for meta-analysis. Additional file 3. Dataset from risk of bias assessment.

\section{Abbreviations}

AMR: Antimicrobial resistance; C3G: Third-generation cephalosporins; DCS: Decreased ciprofloxacin susceptibility; FQNS: Fluoroquinolone nonsusceptibility; FQR: Fluoroquinolone resistance; HIV: Human immunodeficiency virus; MDR: Multidrug resistance; NTS: Non-typhoidal Salmonella; WHO: World Health Organization

\section{Acknowledgements}

We acknowledge Magdalena Jans, a biomedical librarian at KU Leuven (Leuven, Belgium), for her help to build the search strategy and Nic Peeters, a biomedical librarian at the Institute of Tropical Medicine (Antwerp, Belgium), for his help to search for and to retrieve articles in the archives of the Institute of Tropical Medicines and of associated European Institutes.

\section{Authors' contributions}

Bieke Tack: conceptualization, data curation, formal analysis, investigation, methodology, project administration, resources, visualization, writing —original draft preparation, writing — review, and editing. Jolien Vanaenrode: data curation, formal analysis, investigation, resources, and writing-review and editing

Jan Y Verbakel: supervision, formal analysis, methodology, and writing-review and editing

Jaan Toelen: supervision, methodology, and writing — review and editing Jan Jacobs: supervision, methodology, and writing-review and editing All authors read and approved the final manuscript.

\section{Funding}

BT has a scholarship from Research Foundation Flanders (FWO, 1153220 N). In addition, the research was funded by the Baillet-Latour fund. The funders had no role in the study design, data collection and analysis, decision to publish, or preparation of the manuscript.

\section{Availability of data and materials}

The datasets supporting the conclusions of this article are included within the additional files of this article, i.e., Additional Files 2 and 3.

Ethics approval and consent to participate

Not applicable.

\section{Consent for publication}

Not applicable

\section{Competing interests}

The authors declare that they have no competing interests.

\section{Author details}

${ }^{1}$ Department of Clinical Sciences, Institute of Tropical Medicine, Antwerp, Belgium. ${ }^{2}$ Department of Microbiology, Immunology and Transplantation, KU Leuven, Leuven, Belgium. ${ }^{3}$ Faculty of Medicine, KU Leuven, Leuven, Belgium.

${ }^{4}$ Department of Public Health and Primary Care, KU Leuven, Leuven, Belgium. ${ }^{5}$ Department of Development and Regeneration, KU Leuven, Leuven, Belgium. ${ }^{6}$ Division of Woman and Child, Department of Pediatrics, University Hospitals Leuven, Leuven, Belgium.

Received: 18 March 2020 Accepted: 25 May 2020

Published online: 17 July 2020

\section{References}

1. GBD 2017 Disease and Injury Incidence and Prevalence Collaborators SL, Abate D, Abate KH, Abay SM, Abbafati C, Abbasi N, et al. Global, regional, and national incidence, prevalence, and years lived with disability for 354 diseases and injuries for 195 countries and territories, 1990-2017: a systematic analysis for the Global Burden of Disease Study 2017. Lancet (London, England). 2018;392:1789-858. https://doi.org/10.1016/S01406736(18)32279-7.

2. Stanaway JD, Parisi A, Sarkar K, Blacker BF, Reiner RC, Hay SI, et al. The global burden of non-typhoidal salmonella invasive disease: a systematic analysis for the Global Burden of Disease Study 2017. Lancet Infect Dis. 2019;19(12):1312-24. https://doi.org/10.1016/S1473-3099(19)30418-9.

3. Gilchrist JJ, MacLennan CA. Invasive nontyphoidal Salmonella disease in Africa. EcoSal Plus. 2019;8 https://doi.org/10.1128/ecosalplus.ESP-0007-2018.

4. Reddy EA, Shaw AV, Crump JA. Community-acquired bloodstream infections in Africa: a systematic review and meta-analysis. Lancet Infect Dis. 2010;10: 417-32 https://doi.org/10.1016/\$1473-3099(10)70072-4.

5. Crump JA, Sjölund-Karlsson M, Gordon MA, Parry CM. Epidemiology, clinical presentation, laboratory diagnosis, antimicrobial resistance, and antimicrobial management of invasive Salmonella infections. Clin Microbiol Rev. 2015;28:901-37 https://doi.org/10.1128/CMR.00002-15.

6. Feasey NA, Dougan G, Kingsley RA, Heyderman RS, Gordon MA. Invasive non-typhoidal salmonella disease: an emerging and neglected tropical disease in Africa. Lancet. 2012;379:2489-99.

7. World Health Organization. WHO model list of essential medicines for children. 7th ed. Geneva: World health organization; 2019.

8. World Health Organization. WHO model list of essential medicines. 21st ed. Geneva: World Health Organization; 2019. 
9. World Health Organization. Critically important antimicrobials for human medicine. 4th ed. Geneva: World Health Organization; 2013. http://apps. who.int/iris/bitstream/10665/251715/1/9789241511469-eng.pdf?ua=1.

10. World Health Organization. Global action plan on antimicrobial resistance. Geneva: World Health Organization; 2015. https://apps.who.int/iris/ bitstream/handle/10665/193736/9789241509763_eng.pdf?sequence $=1$.

11. Turner P, Fox-Lewis A, Shrestha P, Dance DAB, Wangrangsimakul T, Cusack TP, et al. Microbiology Investigation Criteria for Reporting Objectively (MICRO): a framework for the reporting and interpretation of clinical microbiology data. BMC Med. 2019;17:70 https://doi.org/10.1186/s12916019-1301-1.

12. Munn Z, SM MCS, Lisy K, Riitano D, Tufanaru C. Methodological guidance for systematic reviews of observational epidemiological studies reporting prevalence and cumulative incidence data. Int J Evid Based Healthc. 2015; 13:147-53.

13. Tufanaru C, Munn Z, Aromataris E, Campbell J, Hopp L. Chapter 3: systematic reviews of effectiveness. In: Aromataris E, Munn Z, editors. Joanna Briggs Institute Reviewer's Manual: The Joanna Briggs Institute; 2017. https://joannabriggs.org/sites/default/files/2019-05/JBI_Quasi-Experimental_ Appraisal_Tool2017_0.pdf.

14. Brouwers MC, Kerkvliet K, Spithof K. The AGREE reporting checklist: a tool to improve reporting of clinical practice guidelines. BMJ. 2016;352:11152 https://doi.org/10.1136/bmj.i1152.

15. McArthur A, Klugárová J, Yan H, Florescu S. Innovations in the systematic review of text and opinion. Int J Evid Based Healthc. 2015;13:188-95.

16. United Nations. Standard country or area codes for statistical use. 1999. https://unstats.un.org/unsd/methodology/m49/. Accessed 28 Feb 2020.

17. Clinical and Laboratory Standards Institute. Analysis and presentation of cumulative antimicrobial susceptibility test data - approved guideline. 4th ed. Wayne: Clinical and Laboratory Standards Institute; 2014.

18. Clinical and Laboratory Standards Institute. Performance standards for antimicrobial susceptibility testing supplement M100. 30th ed. Wayne: Clinical and Laboratory Standards Institute; 2020.

19. Clinical and Laboratory Standards Institute. Performance standards for antimicrobial susceptibility testing supplement M100. 22nd ed. Wayne: Clinical and Laboratory Standards Institute; 2012

20. Clinical and Laboratory Standards Institute. Performance standards for antimicrobial susceptibility testing supplement M100. 26th ed. Wayne: Clinical and Laboratory Standards Institute; 2016.

21. Clinical and Laboratory Standards Institute. Performance standards for antimicrobial susceptibility testing supplement M100. 24th ed. Wayne: Clinical and Laboratory Standards Institute; 2014.

22. The European Committee on Antimicrobial Susceptibility Testing. Breakpoint tables for interpretation of MICs and zone diameters version 10. 0. 2020. http://www.eucast.org/clinical_breakpoints/.

23. Magiorakos A-P, Srinivasan A, Carey RB, Carmeli Y, Falagas ME, Giske CG, et al. Multidrug-resistant, extensively drug-resistant and pandrug-resistant bacteria: an international expert proposal for interim standard definitions for acquired resistance. Clin Microbiol Infect. 2012;18:268-81 https://doi.org/10. 1111/J.1469-0691.2011.03570.X.

24. Parry CM, Threlfall EJ. Antimicrobial resistance in typhoidal and nontyphoidal salmonellae. Curr Opin Infect Dis. 2008;21:531-8.

25. Cuypers WL, Jacobs J, Wong V, Klemm EJ, Deborggraeve S, Van Puyvelde S. Fluoroquinolone resistance in Salmonella: insights by whole-genome sequencing. Microb Genomics. 2018;4 https://doi.org/10.1099/mgen.0.000195.

26. Crump JA, Barrett TJ, Nelson JT, Angulo FJ. Reevaluating fluoroquinolone breakpoints for Salmonella enterica serotype Typhi and for non-Typhi salmonellae. Clin Infect Dis. 2003;37:75-81.

27. Humphries RM, Fang FC, Aarestrup FM, Hindler JA. In vitro susceptibility testing of fluoroquinolone activity against Salmonella: recent hanges to CLS standards. Clin Infect Dis. 2012;55:1107-13. https://doi.org/10.1093/cid/cis600.

28. Muthumbi E, Morpeth SC, Ooko M, Mwanzu A, Mwarumba S, Mturi N, et al. Invasive salmonellosis in Kilifi, Kenya. Clin Infect Dis. 2015;61(suppl 4):S290301 https://doi.org/10.1093/cid/civ737.

29. Bachou H, Tylleskär T, Kaddu-Mulindwa DH, Tumwine JK. Bacteraemia among severely malnourished children infected and uninfected with the human immunodeficiency virus-1 in Kampala. Uganda. BMC Infect Dis. 2006; 6:160 https://doi.org/10.1186/1471-2334-6-160.

30. Bahwere P, Levy J, Hennart P, Donnen P, Lomoyo W, Dramaix-Wilmet M, et al. Community-acquired bacteremia among hospitalized children in rural Central Africa. Int J Infect Dis. 2001:5:180-8.
31. Ogunsola FT, Arewa DG, Akinsete IE, Oduyebo OO, Akanmu AS, Odugbemi TO. Aetiology of bacteraemia among adult AIDS patients attending Lagos University Teaching Hospital (LUTH), Lagos, Nigeria. Niger Postgrad Med J. 2009;16:186-92.

32. Lepage P, Bogaerts J, Van Goethem C, Hitimana DG, Nsengumuremyi F. Multiresistant Salmonella typhimurium systemic infection in Rwanda. Clinical features and treatment with cefotaxime | Journal of Antimicrobial Chemotherapy | Oxford Academic. J Antimicrob Chemother. 1990;25(Suppl A):S53-7 https://academic.oup.com/jac/article-abstract/26/suppl_A/53/68953 9? redirectedFrom=fulltext. Accessed 28 Feb 2020.

33. Nielsen MV, Sarpong N, Krumkamp R, Dekker D, Loag W, Amemasor S, et al. Incidence and characteristics of bacteremia among children in rural Ghana. PLoS One. 2012;7(9):e44063 https://doi.org/10.1371/journal.pone.0044063.

34. Kalonji LM, Post A, Phoba M-F, Falay D, Ngbonda D, Muyembe J-J, et al. Invasive Salmonella infections at multiple surveillance sites in the Democratic Republic of the Congo, 2011-2014. Clin Infect Dis. 2015; 61(suppl 4):S346-53 https://doi.org/10.1093/cid/civ713.

35. Lunguya O, Lejon V, Phoba M-F, Bertrand S, Vanhoof R, Glupczynski Y, et al. Antimicrobial resistance in invasive non-typhoid Salmonella from the Democratic Republic of the Congo: emergence of decreased fluoroquinolone susceptibility and extended-spectrum beta lactamases. PLoS Negl Trop Dis. 2013;7:e2103 https://doi.org/10.1371/journal.pntd.0002103.

36. Feasey NA, Masesa C, Jassi C, Faragher EB, Mallewa J, Mallewa M, et al. Three epidemics of invasive multidrug-resistant Salmonella bloodstream infection in Blantyre, Malawi, 1998-2014. Clin Infect Dis. 2015;61(Suppl 4): S363-71 https://doi.org/10.1093/cid/civ691.

37. Marks F, von Kalckreuth $V$, Aaby P, Adu-Sarkodie Y, El Tayeb MA, Ali M, et al. Incidence of invasive salmonella disease in sub-Saharan Africa: a multicentre population-based surveillance study. Lancet Glob Health. 2017;5:e310-23 https://doi.org/10.1016/S2214-109X(17)30022-0.

38. Tabu C, Breiman RF, Ochieng B, Aura B, Cosmas L, Audi A, et al. Differing burden and epidemiology of non-Typhi Salmonella bacteremia in rural and urban Kenya, 2006-2009. PLoS One. 2012;7:e31237 https://doi.org/10.1371/ journal.pone.0031237.

39. Msemo OA, Mbwana J, Mahende C, Malabeja A, Gesase S, Crump JA, et al. Epidemiology and antimicrobial susceptibility of Salmonella enterica bloodstream isolates among febrile children in a rural district in northeastern Tanzania: a cross-sectional study. Clin Infect Dis. 2019;68(Suppl 2):S177-82 https://doi.org/10.1093/cid/ciy1126.

40. Preziosi M, Zimba TF, Lee K, Tomas M, Kinlin S, Nhatave-Paiva C, et al. A prospective observational study of bacteraemia in adults admitted to an urban Mozambican hospital. South African Med J. 2015;105:370-4.

41. Eibach D, Al-Emran HM, Dekker DM, Krumkamp R, Adu-Sarkodie Y, Maria L, et al. The emergence of reduced ciprofloxacin susceptibility in Salmonella enterica causing bloodstream infections in rural Ghana. Clin Infect Dis. 2016; 62(Suppl 1):S32-6. https://doi.org/10.1093/cid/civ757.

42. Maltha J, Guiraud I, Kaboré B, Lompo P, Ley B, Bottieau E, et al. Frequency of severe malaria and invasive bacterial infections among children admitted to a rural hospital in Burkina Faso. PLoS One. 2014;9:e89103.

43. Molyneux EM, Walsh AL, Malenga G, Rogerson S, Molyneux ME. Salmonella meningitis in children in Blantyre, Malawi, 1996-1999. Ann Trop Paediatr. 2000;20:41-4.

44. Gordon MA, Walsh AL, Chaponda M, Soko D, Mbrwinji M, Molyneux ME, et al. Bacteraemia and mortality among adult medical admissions in Malawi predominance of non-typhi salmonellae and Streptococcus pneumoniae. J Inf Secur. 2001:42:44-9.

45. Dougle ML, Hendriks ER, Sanders EJ, Dorigo-Zetsma JW. Laboratory investigations in the diagnosis of septicaemia and malaria. East Afr Med J. 1997;74:353-6.

46. Bejon P, Mwangi I, Ngetsa C, Mwarumba S, Berkley JA, Lowe BS, et al. Invasive Gram-negative bacilli are frequently resistant to standard antibiotics for children admitted to hospital in Kilifi, Kenya. J Antimicrob Chemother. 2005;56:232-5 https://doi.org/10.1093/jac/dki145.

47. Milledge J, Calis JCJ, Graham SM, Phiri A, Wilson LK, Soko D, et al. Aetiology of neonatal sepsis in Blantyre, Malawi: 1996-2001. Ann Trop Paediatr. 2005; 25:101-10.

48. Kariuki S, Revathi G, Kariuki N, Muyodi J, Mwituria J, Munyalo A, et al. Increasing prevalence of multidrug-resistant non-typhoidal salmonellae, Kenya, 1994-2003. Int J Antimicrob Agents. 2005;25:38-43.

49. Blomberg B, Jureen R, Manji KP, Tamim BS, Mwakagile DSM, Urassa WK, et al. High rate of fatal cases of pediatric septicemia caused by gram-negative 
bacteria with extended-spectrum beta-lactamases in Dar es Salaam, Tanzania. J Clin Microbiol. 2005:43:745-9.

50. Kariuki S, Revathi G, Kiiru J, Lowe B, Berkley JA, Hart CA. Decreasing prevalence of antimicrobial resistance in non-typhoidal Salmonella isolated from children with bacteraemia in a rural district hospital, Kenya. Int J Antimicrob Agents. 2006;28:166-71.

51. Ikumapayi UN, Antonio M, Sonne-Hansen J, Biney E, Enwere G, Okoko B, et al. Molecular epidemiology of community-acquired invasive non-typhoidal Salmonella among children aged 2-29 months in rural Gambia and discovery of a new serovar, Salmonella enterica Dingiri. J Med Microbiol. 2007:56:1479-84.

52. Gbadoé AD, Lawson-Evi K, Dagnra AY, Guédénon K, Géraldo A, Djadou E, et al. Les salmonelloses chez l'enfant au CHU Tokoin de Lomé (Togo). Med Mal Infect. 2008;38:8-11.

53. Seydi M, Soumare M, Sow Al, Diop SA, Sow I, Dieng AB, et al. Étude descriptive des bactériémies à Salmonella non typhi chez les patients infectés par le VIH au CHU de Dakar (Sénégal). Med Mal Infect. 2008;38:25-8.

54. Mayanja BN, Todd J, Hughes P, Van Der Paal L, Mugisha JO, Atuhumuza E, et al. Septicaemia in a population-based HIV clinical cohort in rural Uganda, 1996-2007: incidence, aetiology, antimicrobial drug resistance and impact of antiretroviral therapy. Tropical Med Int Health. 2010;15:697-705.

55. Tapia MD, Tennant SM, Bornstein K, Onwuchekwa U, Tamboura B, Maiga A, et al. Invasive nontyphoidal Salmonella infections among children in Mali, 2002-2014: Microbiological and epidemiologic features guide vaccine development. Clin Infect Dis. 2015. https://doi.org/10.1093/cid/civ729.

56. Keddy KH, Sooka A, Musekiwa A, Smith AM, Ismail H, Tau NP, et al. Clinical and microbiological features of Salmonella meningitis in a South African population, 2003-2013. Clin Infect Dis. 2015;61(Suppl 4):S72-82. https://doi. org/10.1093/cid/civ685.

57. Oneko M, Kariuki S, Muturi-Kioi V, Otieno K, Otieno VO, Williamson JM, et al. Emergence of community-acquired, multidrug-resistant invasive nontyphoidal Salmonella disease in rural Western Kenya, 2009-2013 PubMed. Clin Infect Dis. 2015;61(Suppl 4):s310-S360 https://academic.oup. com/cid/article/61/suppl_4/S310/457833. Accessed 28 Feb 2020.

58. Keddy KH, Musekiwa A, Sooka A, Karstaedt A, Nana T, Seetharam S, et al. Clinical and microbiological features of invasive nontyphoidal Salmonella associated with HIV-infected patients, Gauteng Province, South Africa. Medicine (Baltimore). 2017;96:e6448 https://doi.org/10.1097/MD. 0000000000006448.

59. Tam P-YI, Musicha P, Kawaza K, Cornick J, Denis B, Freyne B, et al. Emerging resistance to empiric antimicrobial regimens for pediatric bloodstream infections in Malawi. Clin Infect Dis. 2019;69:61-8.

60. Kariuki S, Mbae C, Onsare R, Kavai SM, Wairimu C, Ngetich R, et al. Multidrug-resistant nontyphoidal Salmonella hotspots as targets for vaccine use in management of infections in endemic settings. Clin Infect Dis. 2019; 68(Supplement_1):S10-5 https://doi.org/10.1093/cid/ciy898.

61. Mitiku H, Weldegebreal F, Marami D, Teklemariam Z. Nontyphoidal Salmonella bacteremia in antiretroviral therapy-naive HIV-infected individuals at three public hospitals in eastern Ethiopia: prevalence, antimicrobial susceptibility patterns, and associated factors. HIV/AIDS - Res Palliat Care. 2019;11:23-9.

62. Labi AK, Obeng-Nkrumah N, Addison NO, Donkor ES. Salmonella blood stream infections in a tertiary care setting in Ghana. BMC Infect Dis. 2014;14: 3857.

63. Kariuki S, Revathi G, Kariuki N, Kiiru J, Mwituria J, Hart CA. Characterisation of community acquired non-typhoidal Salmonella from bacteraemia and diarrhoeal infections in children admitted to hospital in Nairobi, Kenya. BMC Microbiol. 2006;6:101.

64. Babirekere-Iriso E, Musoke P, Kekitiinwa A. Bacteraemia in severely malnourished children in an HIV-endemic setting. Ann Trop Paediatr. 2006; 26:319-28.

65. Mandomando I, MacEte E, Sigaúque B, Morais L, Quintó L, Sacarlal J, et al. Invasive non-typhoidal Salmonella in Mozambican children. Tropical Med Int Health. 2009;14:1467-74.

66. Fashae K, Ogunsola F, Aarestrup FM, Hendriksen RS. Antimicrobial susceptibility and serovars of Salmonella from chickens and humans in Ibadan, Nigeria. J Infect Dev Ctries. 2010;4:484-94.

67. Moon TD, Silva WP, Buene M, Morais L, Valverde E, Vermund SH, et al. Bacteremia as a cause of fever in ambulatory, HIV-infected Mozambican adults: results and policy implications from a prospective observational study. PLoS One. 2013;8:e83591.
68. Eibach D, Campos CB, Krumkamp R, Al-Emran HM, Dekker D, Boahen KG, et al. Extended spectrum beta-lactamase producing Enterobacteriaceae causing bloodstream infections in rural Ghana, 2007-2012. Int J Med Microbiol. 2016;306:249-54.

69. Darboe S, Okomo U, Muhammad A-K, Ceesay B, Jallow M, Usuf E, et al. Community-acquired invasive bacterial disease in urban Gambia, 20052015: a hospital-based surveillance. Clin Infect Dis. 2019;69(Supplement_2): S105-13 https://doi.org/10.1093/cid/ciz463.

70. Tapia MD, Tennant SM, Bornstein K, Onwuchekwa U, Tamboura B, Maiga A, et al. Invasive nontyphoidal Salmonella infections among children in Mali, 20022014: microbiological and epidemiologic features guide vaccine development. Clin Infect Dis. 2015;61(Suppl 4):S332-8 https://doi.org/10.1093/cid/civ729.

71. Keddy KH, Dwarika S, Crowther P, Perovic O, Wadula J, Hoosen A, et al. Genotypic and demographic characterization of invasive isolates of Salmonella typhimurium in HIV co-infected patients in South Africa. J Infect Dev Ctries. 2009;3:585-92.

72. Vandenberg O, Nyarukweba DZ, Ndeba PM, Hendriksen RS, Barzilay EJ, Schirvel C, et al. Microbiologic and clinical features of Salmonella species isolated from bacteremic children in eastern Democratic Republic of Congo. Pediatr Infect Dis J. 2010;29:504-10.

73. Groß U, Amuzu SK, de Ciman R, Kassimova I, Groß L, Rabsch W, et al. Bacteremia and antimicrobial drug resistance over time. Ghana Emerg Infect Dis. 2011;17:1879-82.

74. Aubry P, Niyongabo T, Nizigiye J, Muhirwa G, Kamanfu G, Ndahiragije A, et al. Bacteremia caused by non-typhoid Salmonellas during an infection by the human immunodeficiency virus (HIV) in the African adult. Med Trop (Mars). 1992;52:447-50 http://www.ncbi.nlm.nih.gov/pubmed/1494316. Accessed 28 Feb 2020

75. Graham SM, Molyneux EM, Walsh AL, Cheesbrough JS, Molyneux ME, Hart CA. Nontyphoidal Salmonella infections of children in tropical Africa. Pediatr Infect Dis J. 2000;19:1189-96.

76. Gordon MA, Banda HT, Gondwe M, Gordon SB, Walsh AL, Phiri A, et al. Nontyphoidal salmonella (NTS) bacteraemia in Malawian adults: a severe, recrudescent, HIV-associated illness. Malawi Med J. 2003;15:47-51. https:// doi.org/10.4314/mmj.v15i2.10776.

77. Lepage P, Bogaerts J, Nsengumuremyi F, Hitimana DG, Van Goethem C, Vandepitte J, et al. Severe multiresistant Salmonella typhimurium systemic infections in Central Africa--clinical features and treatment in a paediatric department - PubMed. J Antimicrob Chemother. 1984;14(Suppl B):153-9 https://academic.oup.com/jac/article-lookup/doi/10.1093/jac/14.suppl_b.153. Accessed 5 Mar 2020.

78. Cheesbrough JS, Mwema Fl, Green SD, Tillotson GS. Quinolones in children with invasive salmonellosis. Lancet (London, England). 1991;338:127. https:// doi.org/10.1016/0140-6736(91)90127-b.

79. Gordon MA, Kankwatira AMK, Mwafulirwa G, Walsh AL, Hopkins MJ, Parry $\mathrm{CM}$, et al. Invasive non-typhoid salmonellae establish systemic intracellular infection in HIV-infected adults: an emerging disease pathogenesis. Clin Infect Dis. 2010;50:953-62 https://doi.org/10.1086/651080.

80. Molyneux EM, Mankhambo LA, Ajib P, Graham SM, Forsyth H, Amos P, et al. The outcome of non-typhoidal Salmonella meningitis in Malawian children, 1997-2006. Ann Trop Paediatr. 2009;29:13-22.

81. Graham SM, Walsh AL, Molyneux EM, Phiri AJ, Molyneux ME. Clinical presentation of non-typhoidal Salmonella bacteraemia in Malawian children. Trans R Soc Trop Med Hyg. 2000;94:310-4 https://doi.org/10.1016/S00359203(00)90337-7.

82. De Canvalho EM, Martinelli R, De Oliveira MMG, Roche H. Cefamandole treatment of salmonella bacteremia. Antimicrob Agents Chemother. 1982;21:334-5.

83. Soe GB, Overturf GD. Treatment of typhoid fever and other systemic salmonelloses with cefotaxime, ceftriaxone, cefoperazone, and other newer cephalosporins. Rev Infect Dis. 1987;9:719-36.

84. Wang J-H, Liu Y-C, Yen M-Y, Wang J-H, Chen Y-S, Wann S-R, et al. Mycotic aneurysm due to non-typhi Salmonella: report of 16 cases. Clin Infect Dis. 1996;23:743-7.

85. Chiu CH, Chuang CH, Chiu S, Su LH, Lin TY. Salmonella enterica serotype choleraesuis infections in pediatric patients. Pediatrics. 2006;117:e1193-6.

86. Forrest GN, Wagner LAM, Talwani R, Gilliam BL. Lack of fluoroquinolone resistance in non-typhoidal salmonella bacteremia in HIV-infected patients in an urban US setting. J Int Assoc Phys AIDS Care. 2009;8:338-41.

87. Tsai MH, Huang YC, Chiu CH, Yen MH, Chang LY, Lin PY, et al. Nontyphoidal Salmonella bacteremia in previously healthy children: analysis of 199 episodes. Pediatr Infect Dis J. 2007;26:909-13. 
88. Hess LM, Burdick B, Minard CG, Dutta A. IV antibiotic durations for nontyphoidal Salmonella bacteremia. Hosp Pediatr. 2019;9:993-7 https://doi. org/10.1542/hpeds.2019-0231.

89. Marchou B, Meurisse JJ. Salmonelloses. Aspects thérapeutiques. Med Mal Infect. 1992;22(SUPPL. 3):340-7.

90. Hohmann EL. Nontyphoidal Salmonellosis. Clin Infect Dis. 2001;32:263-9.

91. Wen SCH, Best E, Nourse C. Non-typhoidal Salmonella infections in children: review of literature and recommendations for management. J Paediatr Child Health. 2017;53:936-41 https://doi.org/10.1111/jpc.13585.

92. Sperber SJ, Schleupner CJ. Salmonellosis during infection with human immunodeficiency virus. Rev Infect Dis. 1987;9:925-34.

93. Maloney WJ, Guerrant RL. Epidemiology, therapy, and prevention of infection with Salmonella organisms. Curr Opin Infect Dis. 1992;5:74-9 https://doi.org/10.1097/00001432-199202000-00013.

94. Kovacs A, Leaf HL, Simberkoff MS. Bacterial infections. Med Clin North Am. 1997;81:319-43.

95. Goldberg MB, Rubin RH. The spectrum of Salmonella infection. Infect Dis Clin N Am. 1988;2:571-98 http://www.ncbi.nlm.nih.gov/pubmed/3074116. Accessed 5 Mar 2020.

96. Chen HM, Wang Y, Su LH, Chiu CH. Nontyphoid Salmonella infection: microbiology, clinical features, and antimicrobial therapy. Pediatrics Neonatol. 2013;54:147-52.

97. Panel on Opportunistic Infections in Adults and Adolescents with HIV. Guidelines for the prevention and treatment of opportunistic infections in adults and adolescents with HIV: recommendations from the Centers for Disease Control and Prevention, the National Institutes of Health, and the HIV Medicine Association of the Inf. 2019. http://aidsinfo.nih.gov/ contentfiles/lvguidelines/adult_oi.pdf. Accessed 6 Aug 2019.

98. Gilbert DN, Chambers HF, Eliopoulos GM, Saag MS, Pavia AT. The Sanford guide to antimicrobial therapy. 48th ed. Sperryvile: Antimicrobial Therapy, Inc; 2018.

99. Owusu-Ofori A, Scheld WM. Treatment of Salmonella meningitis: two case reports and a review of the literature. Int J Infect Dis. 2003;7:53-60.

100. Astruc J, Rodiere M. Les salmonelloses en pédiatrie. Med Mal Infect. 1992; 22(SUPPL. 3):299-309.

101. Kariuki S, Gordon MA, Feasey N, Parry CM. Antimicrobial resistance and management of invasive Salmonella disease. Vaccine. 2015;33(Suppl 30 3): C21-9. https://doi.org/10.1016/j.vaccine.2015.03.102.

102. Stoycheva MV, Murdjeva MA. Antimicrobial therapy of salmonelloses-current state and perspectives. Folia Med (Plovdiv). 2006:48:5-10 http:// www.ncbi.nlm.nih.gov/pubmed/16918048. Accessed 19 Feb 2020.

103. Kinsella TR, Yogev R, Shulman ST, Gilmore R, Chadwick EG. Treatment of Salmonella meningitis and brain abscess with the new cephalosporins: two case reports and a review of the literature. Pediatr Infect Dis J. 1987;6:476-80.

104. Sánchez-Vargas FM, Abu-El-Haija MA, Gómez-Duarte OG. Salmonella infections: an update on epidemiology, management, and prevention. Travel Med Infect Dis. 2011;9:263-77.

105. Graham SM, English M. Non-typhoidal salmonellae: a management challenge for children with community-acquired invasive disease in tropical African countries. Lancet. 2009:373:267-9.

106. Committee on infectious diseases, American Academy of Pediatrics, Kimberlin D, Brady MT, Jackson MA, Long SS. Summaries of infectious diseases. In: Red Book. 31st ed. Itasca: American Academy of Pediatrics; 2018. p. 711-8.

107. Robinson JL. Salmonella infections in Canadian children. Paediatr Child Health. 2019;24:50-1.

108. Cohen R, Raymond J, Gendrel D. Antimicrobial treatment of diarrhea/acute gastroenteritis in children. Arch Pediatr. 2017;24:S26-9.

109. Morpeth SC, Ramadhani HO, Crump JA. Invasive non-typhi Salmonella disease in Africa. Clin Infect Dis. 2009:49:606-11.

110. Chimalizeni Y, Kawaza K, Molyneux E. The epidemiology and management of non typhoidal salmonella infections. Adv Exp Med Biol. 2010;659:33-46.

111. Bula-Rudas FJ, Rathore MH, Maraqa NF. Salmonella infections in childhood. Adv Pediatr Infect Dis. 2015;62:29-58.

112. Worsena CR, Miller AS, King MA. Salmonella infections. Pediatr Rev. 2019;40: 543-5.

113. Geme JW, Hodes HL, Marcy SM, Pickering LK, Rodriguez WJ, McCracken GH, et al. Consensus: management of Salmonella infection in the first year of life. Pediatr Infect Dis J. 1988;7:615-21 http://www.ncbi.nlm.nih.gov/ pubmed/3050857. Accessed 19 Feb 2020.
114. Ruiz M, Rodríguez JC, Escribano I, Royo G. Available options in the management of non-typhi Salmonella. Expert Opin Pharmacother. 2004;5:1737-43.

115. Gendrel D, Cohen R. Diarrhées bactériennes et antibiotiques: les recommandations européennes. Arch Pediatr. 2008;15(SUPPL. 2):S93-6.

116. Alghasham AA, Nahata MC. Clinical use of fluoroquinolones in children. Ann Pharmacother. 2000;34:347-59.

117. Blaison G, Christmann D, Storck D. Salmonelles mineures: place des fluoroquinolones dans le traitement de l'infection déclarée et du portage asymptomatique. J Méd Strasbg. 1992;23:364-7.

118. Pechère JC. Quinolones in intracellular infections. Drugs. 1993;45:29-36.

119. Robinson JL. Salmonella infections in Canadian children | Canadian Paediatric Society. 2018. https://www.cps.ca/en/documents/position/ salmonella-infections-in-canadian-children. Accessed 17 Dec 2019.

120. Bryan JP, Rocha H, Scheld WM, Bryan JP, Rocha H, Scheld WM. Problems in salmonellosis: rationale for clinical trials with newer $\beta$-lactam agents and quinolones. Rev Infect Dis. 1986;8:189-207.

121. McMullan BJ, Andresen D, Blyth CC, Avent ML, Bowen AC, Britton PN, et al. Antibiotic duration and timing of the switch from intravenous to oral route for bacterial infections in children: systematic review and guidelines. Lancet Infect Dis. 2016;16:e139-52. https://doi.org/10.1016/S1473-3099(16)30024-X.

122. Bryan JP, Rocha H, Scheid WM. Problems in salmonellosis: rationale for clinical trials with newer -lactam agents and quinolones. Clin Infect Dis. 1986:8:189-207 https://doi.org/10.1093/clinids/8.2.189.

123. Kariuki S, Gordon MA, Feasey N, Parry CM. Antimicrobial resistance and management of invasive Salmonella disease. Vaccine. 2015;33:C21-9 https:// doi.org/10.1016/j.vaccine.2015.03.102.

124. Felmingham D, Farrell DJ. In vitro activity of telithromycin against Gram-negative bacterial pathogens. J Inf Secur. 2005. https://doi.org/10.1016/j.jinf.2005.05.014.

125. Clinical and Laboratory Standards Institute. Performance standards for antimicrobial susceptibility testing supplement M100. 29th ed. Wayne: Clinical and Laboratory Standards Institute; 2019.

126. Watson KC. Tetracycline in typhoid fever. Lancet. 1955;265:646-7.

127. Wang X, Biswas S, Paudyal N, Pan H, Li X, Fang W, et al. Antibiotic resistance in Salmonella typhimurium isolates recovered from the food chain through National Antimicrobial Resistance Monitoring System between 1996 and 2016. Front Microbiol. 2019;10(MAY):985. https://doi.org/10.3389/fmicb.2019.00985.

128. European Centre for Disease Prevention and Control. EU protocol for harmonised monitoring of antimicrobial resistance in human Salmonella and Campylobacter isolates - June 2016: Stockholm; 2016. https://www. ecdc.europa.eu/en/publications-data/eu-protocol-harmonised-monitoringantimicrobial-resistance-human-salmonella-and-0. Accessed 25 Mar 2020.

129. Browne AJ, Kashef Hamadani BH, Kumaran EAP, Rao P, Longbottom J, Harriss E, et al. Drug-resistant enteric fever worldwide, 1990 to 2018: a systematic review and meta-analysis. BMC Med. 2020;18:1.

130. Britto CD, Wong VK, Dougan G, Pollard, Andrew J. A systematic review of antimicrobial resistance in Salmonella enterica serovar Typhi, the etiological agent of typhoid. PLoS Negl Trop Dis. 2018:1-15. https://doi.org/10.1371/ journal.pntd.0006779.

131. Tadesse G, Tessema TS, Beyene G, Aseffa A. Molecular epidemiology of fluoroquinolone resistant Salmonella in Africa: a systematic review and meta-analysis. PLoS One. 2018;13:e0192575.

132. World Health Organization. Background document: the diagnosis, treatment and prevention of typhoid fever. Geneva: World health organization; 2003.

133. World Health Organization. WHO recommendations on child health. Geneva: World health organization; 2017.

134. Onwuezobe IA, Oshun PO, Odigwe CC. Antimicrobials for treating symptomatic non-typhoidal Salmonella infection. Cochrane Database Syst Rev. 2012;11(11):CD001167 https://doi.org/10.1002/14651858.CD001167.pub2.

135. Guarino A, Ashkenazi S, Gendrel D, Lo Vecchio A, Shamir R, Szajewska H. European society for pediatric gastroenterology, hepatology, and nutrition/ European Society For Pediatric Infectious Diseases evidence-based guidelines for the management of acute gastroenteritis in children in Europe: update 2014. J Pediatr Gastroenterol Nutr. 2014;59:132-52.

136. Ombelet S, Ronat JB, Walsh T, Yansouni CP, Cox J, Vlieghe E, et al. Clinical bacteriology in low-resource settings: today's solutions. Lancet Infect Dis. 2018:18:e248-58.

137. Tack B, Phoba MF, Barbé B, Kalonji LM, Hardy L, Van Puyvelde S, et al. Nontyphoidal Salmonella bloodstream infections in Kisantu, DR Congo: emergence of O5-negative Salmonella typhimurium and extensive drug resistance. PLoS Negl Trop Dis. 2020;14(4):e0008121. https://doi.org/10.1371/journal.pntd. 0008121 eCollection 2020 Apr. 
138. Keij FM, Kornelisse RF, Hartwig NG, Reiss IKM, Allegaert K, Tramper-Stranders GA. Oral antibiotics for neonatal infections: a systematic review and metaanalysis. J Antimicrob Chemother. 2019;74:3150-61 https://doi.org/10.1093/ $\mathrm{jac} / \mathrm{dkz} 252$.

139. van den Berg M, Ogutu B, Sewankambo NK, Merten S, Biller-Andorno N, Tanner M. Clinical trials in low-resource settings: the perspectives of caregivers of paediatric participants from Uganda, Tanzania and Kenya. Tropical Med Int Health. 2019;24(8):1023-30 https://doi.org/10.1111/tmi. 13281. Epub 2019 Jul 1.

140. Li HK, Agweyu A, English M, Bejon P. An unsupported preference for intravenous antibiotics. PLoS Med. 2015;12:e1001825.

141. Tennant SM, MacLennan CA, Simon R, Martin LB, Khan MI. Nontyphoidal salmonella disease: current status of vaccine research and development. Vaccine. 2016;34:2907-10 https://doi.org/10.1016/J.VACCINE.2016.03.072.

142. Post AS, Diallo SN, Guiraud I, Lompo P, Tahita MC, Maltha J, et al. Supporting evidence for a human reservoir of invasive non-typhoidal Salmonella from household samples in Burkina Faso. PLoS Negl Trop Dis. 2019;13:e0007782.

143. Phoba M-F, Barbé B, Ley B, Van Puyvelde S, Post A, Mattheus W, et al. High genetic similarity between non-typhoidal Salmonella isolated from paired blood and stool samples of children in the Democratic Republic of the Congo. PLoS Negl Trop Dis. Accepted for publication.

\section{Publisher's Note}

Springer Nature remains neutral with regard to jurisdictional claims in published maps and institutional affiliations.

Ready to submit your research? Choose BMC and benefit from:

- fast, convenient online submission

- thorough peer review by experienced researchers in your field

- rapid publication on acceptance

- support for research data, including large and complex data types

- gold Open Access which fosters wider collaboration and increased citations

- maximum visibility for your research: over $100 \mathrm{M}$ website views per year

At $\mathrm{BMC}$, research is always in progress.

Learn more biomedcentral.com/submissions 